\title{
Introducción al boxeo \\ de la flor del ciruelo: \\ historia, cultura y \\ práctica
}

ZHANG GUODONG

Southwest University (República Popular China)

Thomas Green

Texas A\& M University (EE.UU.)

Recibido 01/09/2010 - Aceptado 01/11/2010

\section{Resumen}

El meihuaquan ("Puño [Boxeo] de la Flor del Ciruelo") se ha practicado tradicionalmente como arte vernáculo (folclórico) en el grupo étnico de los Han de las provincias chinas de Shandong, Henan y Hebei. Los registros históricos datan al boxeo de la flor del ciruelo del s. XVII. La novela clásica china Shuǐhǔ Zhuàn (Las crónicas del pantano) relata las proezas marciales de los héroes proscritos de Shandong durante el siglo XII, quienes también podían haber sido boxeadores mei. Así, durante posiblemente un milenio, la región ha sido célebre por sus artes marciales vernáculas y el bandolerismo social. La rampante anarquía de la región promovió habilidades marciales altamente desarrolladas tanto entre los criminales como entre aquellos que necesitaban defenderse frente a los bandidos. Los factores culturales, económicos y ambientales de la región dieron lugar a creencias políticas y religiosas heterodoxas que sirvieron frecuentemente como catalizadoras de sectas marciales, muy destacadamente los "Bóxers", que en el cambio al s. XX entraron en conflicto con el gobierno imperial. Estos factores sentaron las bases de los "rasgos de carácter" del arte, mientras que el taoísmo, la teoría de los cinco elementos y un concepto del cambio predecible conformaron los principios estratégicos y mecánicos del boxeo de la flor del ciruelo. Durante la última década se han realizado esfuerzos para globalizar este arte marcial vernáculo. Es probable que esta circunstancia, en vez de conducir al boxeo de la flor del ciruelo a la extinción, consiga que lo tradicional y lo "más amplio que lo local" lleguen a coexistir.

Palabras clave: Provincia de Shandong, bóxers, folklore, filosofía marcial, modernización.

\section{An Introduction to Plum Blossom Boxing: History, Culture and Practice}

Abstract: Meihuaquan ("Plum Blossom Fist [Boxing]") has traditionally been practiced as vernacular (folk) art practiced among the Han ethnic group residing in the Shandong, Henan and Hebei Provinces of China. Historical documentation dates Plum Blossom Boxing to the seventeenth century. The classic Chinese novel, Shuiȟ ̌̌ Zhuàn (Marsh

Todas las fotografías son cortesía de Li Yun, excepto cuando se señale lo contrario. 
Chronicles) recounts the martial exploits of Shandong's twelfth century outlaw heroes who may have been M ei Boxers, also. Thus, for perhaps a millennium, the region has been noted for vernacular martial arts and social banditry. The region's rampant lawlessness promoted highly-developed martial prowess among both lawbreakers and those who were required to protect themselves against the brigands. Cultural, economic, and environmental factors in the region gave rise to heterodox political and religious beliefs that frequently served as a catalyst for martial sects, most notably the "Boxers" who at the turn of the twentieth century, came into conflict with the imperial government. These factors laid the groundwork for the "character traits" of the art while Taoism, the Five Elements theory, and a concept of predictable change shaped Plum Boxing's strategic and mechanical principles. In the past decade, there have been efforts to globalize this vernacular martial art. Rather than driving Plum Boxing to extinction it is likely that the folk and the "larger than local" will co-exist.

Key words: Shandong Province, Boxers, folklore, martial philosophy, modernization.

\section{Introdução ao boxe flor de ameixa: história, cultura e prática}

Resumo: 0 meihuaquan ("Punho [Boxe] da Flor de Ameixa") praticou-se tradicionalmente como arte vernácula (folclórica) no grupo étnico dos Han, das províncias chinesas de

W ANG ZHONGYUN PRACTICANDO LA POSTURA ENGAÑOSA CON LA ESPADA.

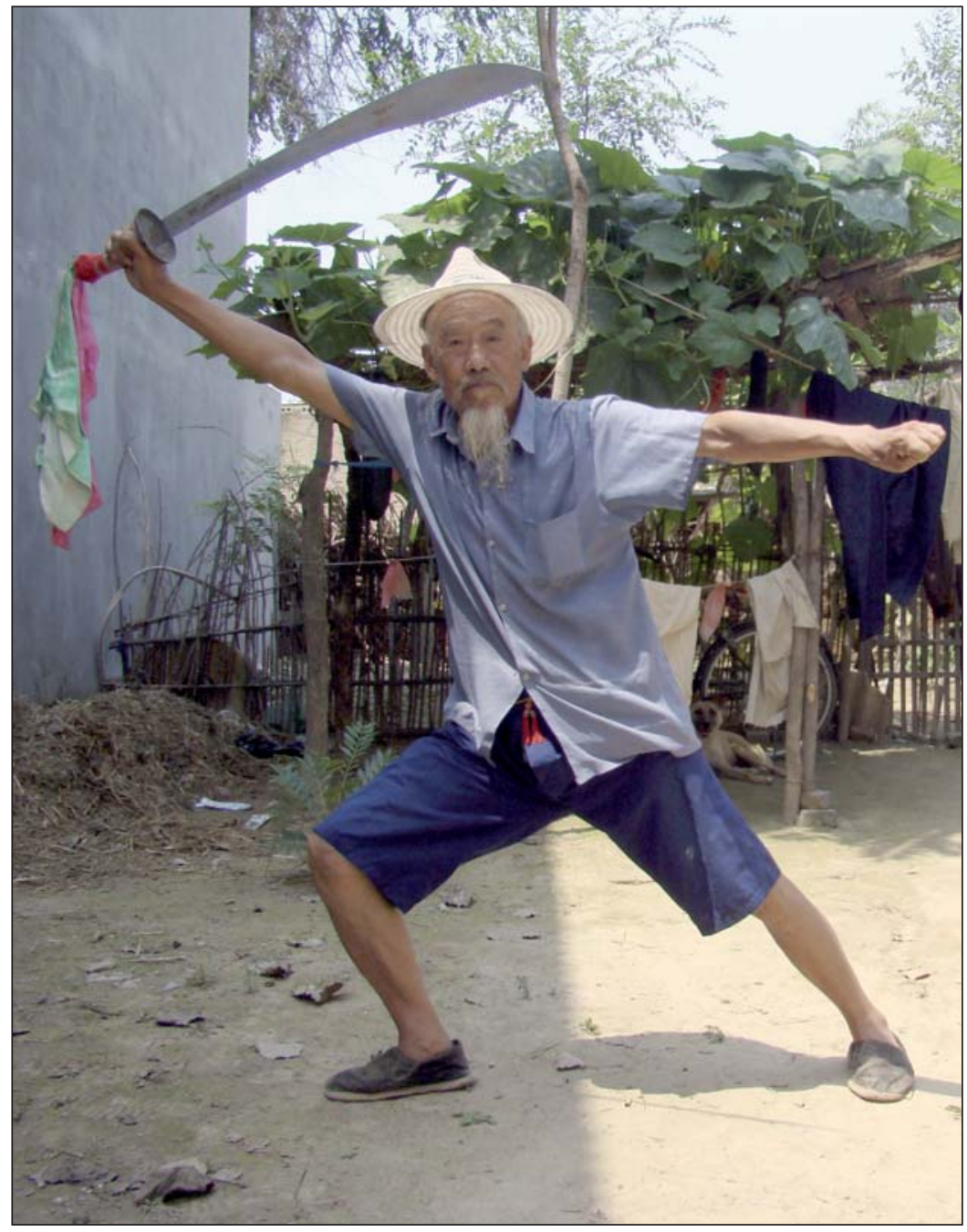

Shandong, Henan e Hebei. Os registos históricos datam o boxe flor de ameixa do século XVII. A crónica clássica chinesa Shuǐhǔ Zhuàn (As Crónicas do Pântano) relata as proezas marciais dos heróis proscritos de Shandong durante o século XII, que também podiam ter sido "boxeurs" mei. Assim, durante possivelmente um milénio, a região foi célebre pelas suas artes marciais vernáculas e de banditismo social. A aparente anarquia da região promoveu habilidades marciais altamente desenvolvidas, tanto entre os criminosos como entre aqueles que necessitavam de se defender frente aos bandidos. Os factores culturais, económicos e ambientais da região deram lugar a crenças políticas e religiosas heterodoxas que serviram frequentemente como catalisadoras de seitas marciais, muito destacadamente os "boxeurs", que na transição do século $X X$ entraram em conflito com o governo Imperial. Estes factores assentaram as bases nos "atributos de carácter" da arte, tal como o taoísmo e a teoria dos cinco elementos, confirmando os princípios estratégicos e mecânicos do boxe flor de ameixa. Durante a última década realizaram-se esforços para globalizar esta arte marcial vernácula. Mais do que conduzir o boxe flor de ameixa à extinção, é provável que 0 tradicional e o "mais amplo que o local" cheguem a coexistir.

Palavras-chave: Província de Shandong, boxeur, folclore, filosofia marcial, modernização. 


\section{Introducción al boxeo de la flor del ciruelo: historia, cultura y práctica}

ZHANG GuOdONG

Southwest University (República Popular China)

Thomas Green

Texas A\& M University (EE.UU.)

\section{Introducción}

Para los practicantes del boxeo de la flor del ciruelo (en chino, meihuaquan), la flor del ciruelo (chimonanthus; en chino, mei) encarna tanto significados filosóficos como un modelo de los principios físicos y estratégicos fundamentales del arte. La cultura china reconoce cuatro plantas -ciruelo, bambú, crisantemo y orquídea- como símbolos de las nobles virtudes del confucianismo. El grupo es conocido en conjunto como "Los cuatro caballeros". Las relaciones semióticas de estas cuatro plantas impregnan las tradiciones estéticas, filosóficas y marciales. En el siguiente artículo consideraremos las cualidades simbólicas de la flor del ciruelo aisladamente respecto a las otras tres plantas y su relación con el sistema de boxeo de la flor del ciruelo tal y como se ha perpetuado en las provincias de Shandong y Henan. Específicamente, nos centramos en la expresión tradicional "de marco amplio" del meihuaquan tal y como pervive en las prefecturas de Heze (Shandong) y Puyang (Henan).

Se han seleccionado estas prefecturas debido a que en ellas perviven ancianos maestros y lugares de prácticas del boxeo (un área tipo parque 0 espacio abierto similar donde los residentes se reúnen para practicar sus habilidades marciales). En segundo lugar, estas prefecturas incluyen tres tipos diferentes de municipios clasificados por niveles de modernización: pueblos tradicionales, pueblos en suburbios y comunidades en ciudades modernas. La información fue recogida en las siguientes localizaciones: el Condado de W angfang de Juancheng (provincia de Shandong), Renhuai de Yuncheng, Muli y Dongmagai (Comunidad de Mudan, Heze), Houzhuzhai, Caijicun y Wuzhai (Puyang), todos pueden ser categorizados como pueblos tradicionales. Xiwangtang y Gengzhuang (Zona de Desarrollo de Heze) son pueblos en suburbios. Y Shuangheji, Chaodikou, Luwan y $\mathrm{N}$ anguan (Comunidad de Mudan, Heze) están incorporados al entorno urbano 


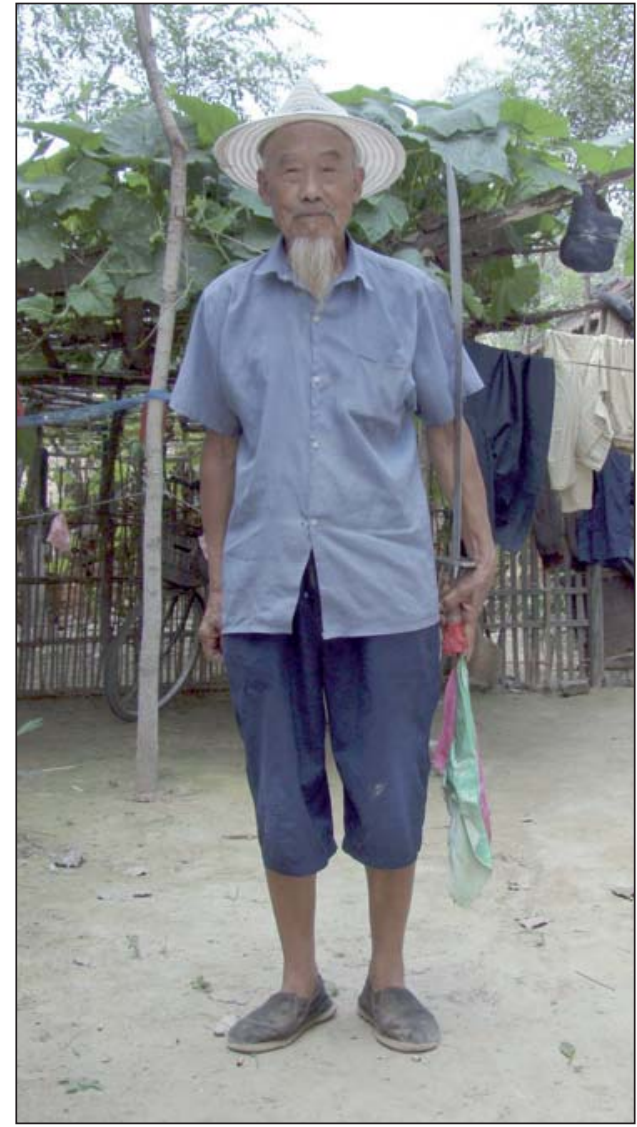

EL MAESTRO W ANG ZHONGYON PRESIDE EL LUGAR DE PRÁCTICA DE BOXEO MEI DE W ANGFANG, EN JUANCHENG.

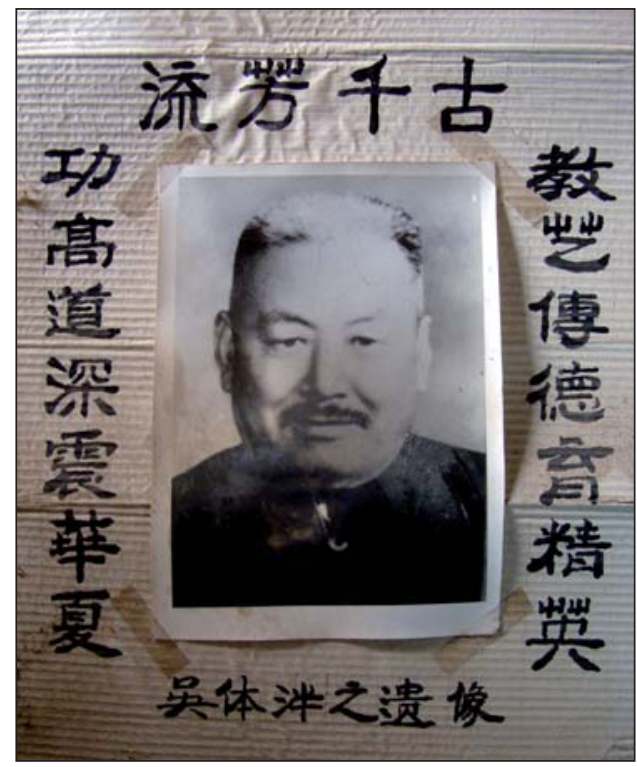

El MAESTRO W U TIPAN. moderno. Las historias tradicionales de los lugares representativos del boxeo y sus respectivos maestros son como siguen.

Juancheng está cerca del Río Amarillo, y antiguamente recibía el nombre de Puzhou. Es la ciudad natal de Sun Bin (m. 316 a.C.), el estratega militar supuestamente descendiente de Sun Tzu, y de W ang Xianzhi (m. 878 d.C.), líder de una revuelta campesina a finales de la dinastía Tang (618-907 d.C). El meihuaquan se difundió de Heze y Puyang a Juancheng a finales de la dinastía Qing (1644-1911). Los lugares de práctica del boxeo mei en Juancheng que han sido famosos en la historia tradicional del arte, además de la localidad de W angfang, son Gaotun, Aizhuang y Jiuchengjie. La historia del lugar de práctica de boxeo mei de W angfang se remonta a principios del s. XX, cuando el maestro W u Tipan (1891-1964) y Si Zhongyuan lo enseñaron allí. W ang Zhongyon (1924- ), un maestro del arte de 15a generación, informa que durante la década de 1980 más del 80\% de las personas que entrenaban en W angfang practicaban meihuaquan, pero que ahora la práctica ha disminuido. La causa principal de esta disminución es el hecho de que la mayoría de personas jóvenes y de mediana edad se han convertido en asalariados urbanos, y habitualmente vuelven al pueblo únicamente para el Festival de Primavera (generalmente conocido en occidente como "Año Nuevo Chino") y la cosecha. A pesar de esto, W angfang mantiene el liangquan (exhibiciones de boxeo) en todos los festivales de primavera. La misma situación se produce en otros lugares de práctica de boxeo mei de otros pueblos tradicionales.

Un ejemplo del segundo tipo (lugar de práctica en entorno suburbano) se localiza en Gengzhuang (Zona de Desarrollo de Heze). Yang Yuanzhi (1932-), un maestro de boxeo mei de 14a generación residente allí, nos contó que este es un lugar donde han entrenado muchos maestros famosos de meihuaquan. Su lista de notables boxeadores incluía los siguientes. Yang Shiwen (1899-1952) aprendió boxeo mei de Li Futian (1886-1958), al que se llama localmente el "héroe del Río Amarillo". Yang fue miembro del equipo de artes marciales de Ma Liang en 1919. También aprendió lucha de W ang Ziping (1881-1973), quien había sido miembro de la sociedad "Puños Rectos y Armoniosos" durante la Rebelión Bóxer y posteriormente sirvió como vicepresidente de la Asociación China de W ushu. Yang fue conservador del Museo de Artes Marciales de Caozhou (Heze) durante sus últimos años de vida. Tras 20 años de crecimiento urbano, la gente de Gengzhuang ha perdido virtualmente toda su tierra agrícola a medida que avanzaba la urbanización. En la actualidad muy pocas personas locales tienen conocimientos de meihuaquan. Yang Yuanzhi informó que en este lugar no se habían realizado exhibiciones de boxeo (liangquan) durante los últimos diez años.

Nanguan ("Puerta del Sur"), en la ciudad de Heze, representa el lugar urbanizado para la práctica del boxeo. A principios del 
s. XX, W u Tipan se trasladó con su familia desde Puyang a la ciudad de Heze. Cuando la construcción de rascacielos desplazó al grupo de su localización original en la puerta sur de la ciudad, se trasladó a una esquina del Estadio Xiguan. En el 2010 veinte boxeadores, cuya edad media es de 60 años, se reúnen allí para practicar meihuaquan temprano cada mañana. En general, los miembros del grupo eran agricultores, pero después de haberse trasladado a la ciudad ahora trabajan en diversas ocupaciones urbanas. El maestro de este grupo es W u Baihua (1936-). Bajo su tutela el grupo ha enviado regularmente equipos de boxeadores a eventos de liangquan durante el presente siglo.

Los linajes de Shandong del boxeo de la flor del ciruelo están estipulados, ya que la etiqueta "Flor de Ciruelo" ha sido ampliamente aplicada a los sistemas de boxeo tradicional en China. Existe un consenso general de que el meihuaquan es un sistema originario de las provincias del noroeste, aunque últimamente no se ha limitado a esta zona como se discutirá más adelante. De acuerdo a la tradición, el estilo original de meihuaquan era un estilo de "marco amplio", significando que los movimientos del cuerpo y las extremidades son amplios, lo que hace que cubran una gran área (el "marco"). A proximadamente hace 200 años, en la octava generación desde el fundador del arte, Zhang Fu creó el meihuaquan de "marco pequeño". Este meihuaquan tuvo un desarrollo relativamente rápido, y su distribución ha sido más amplia. Hanqi Chang ( -1988) ayudó a difundirlo tras trasladarse de Hebei a Beijing en la década de 1930. Su discípulo Yan Zijie (1938- ) ha llevado el estilo a los continentes americano y europeo tras retirarse de
ARRIBA:

El maestro Yang YuanzhI CON EL GUAN-DO.

ABAJO:

LUGAR DE PRÁCTICA DEL BOXEO EN NANGUAN (CIUdAd DE HEZE).

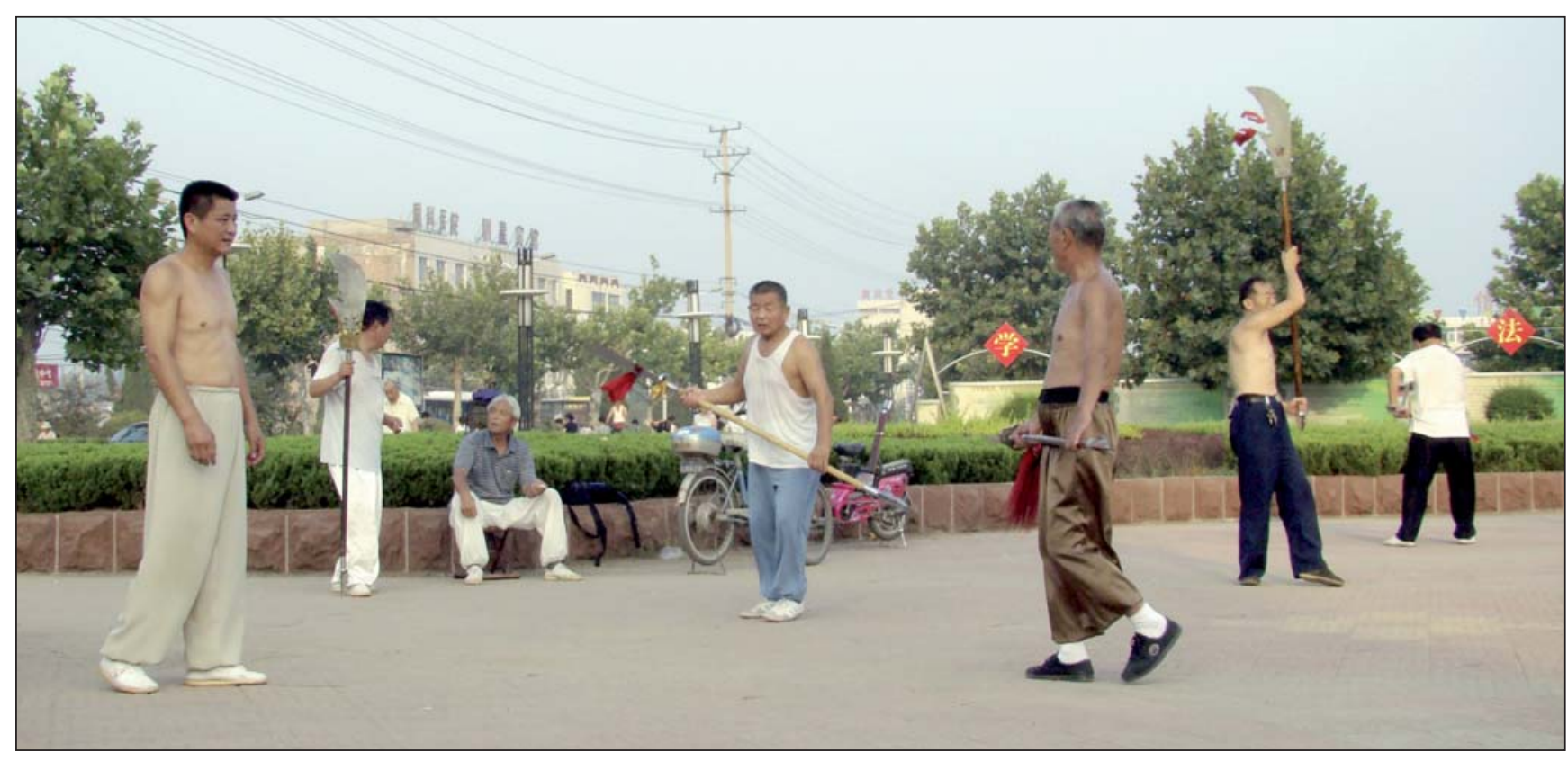

Zhang $\&$ Green $\diamond$ Introducción al boxeo de la flor del ciruelo... 


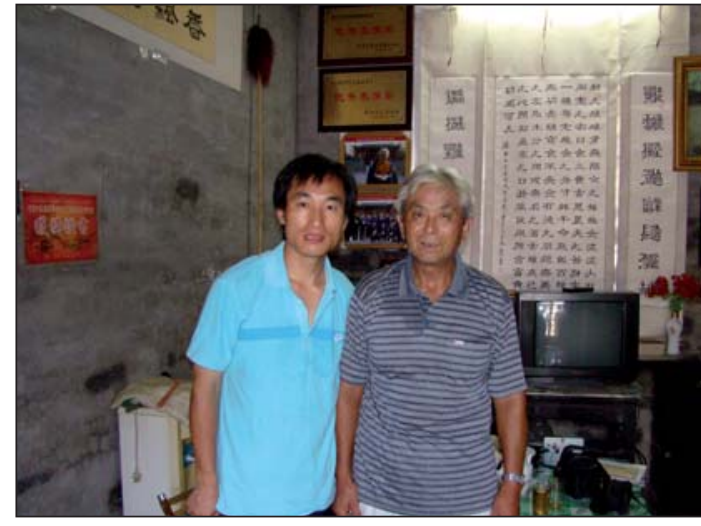

W u BalHua (Derecha) y Zhang Guodong EN CASA DE W U.

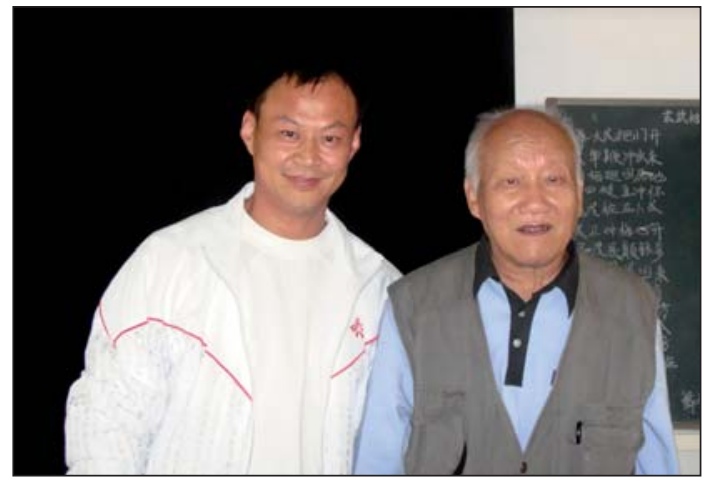

Sang Quanxi y Yan Zijie (derecha) en el Segundo Evento Internacional de Liangquan DE LIANGSHAN, EN 2010.

Cortesía de Sang Quanxi.

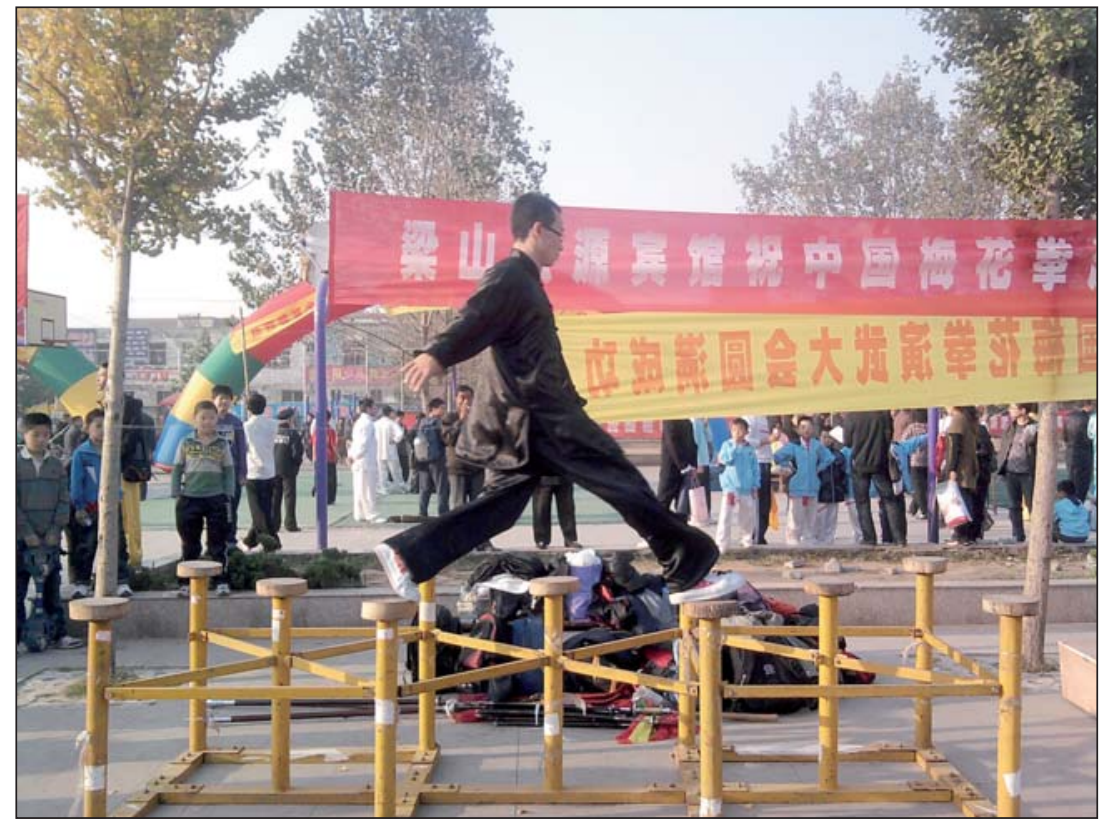

su puesto de profesor de matemáticas en la Universidad de Shandong. En Heze y Puyang aún prevalece el estilo más tradicional de "marco amplio".

Algunos sistemas de la flor del ciruelo compiten por destacar los atributos distintivos de sus propias variantes locales de meihuaquan, adoptando nombres tales como "Flor Lunar de Ciruelo", "Flor Central de Ciruelo", "Flor Periférica de Ciruelo", "Flor Maestra de Ciruelo" y demás. Incluso en las provincias cercanas a su lugar de origen, el sistema puede diferenciarse según localidades, como el meihuaquan Leijia (meihuaquan practicado en el pueblo de Leijia, al suroeste de Shandong), según un "linaje de sangre" como en el meihuaquan Baijiazhi (meihuaquan fundado por la familia Bai). Más aún, cualquier sistema que incorpore el hombre mei no tiene por qué relacionarse necesariamente con el boxeo de la flor del ciruelo.

Para añadir más confusión, algunas formas individuales de sistemas que no reclaman ser ramificaciones de meihuaquan pueden ser etiquetadas como "puños de flor de ciruelo". Un ejemplo puede ser el "meihuaquan Hongjia" (el linaje Hong del boxeo de la flor del ciruelo), que es una de las formas de un sistema que tradicionalmente se cree relacionado con el hung gar. Un aparato para el entrenamiento, denominado "pilares de la flor del ciruelo" (postes o "pilotes"), que consiste en una serie de postes (de aproximadamente $60 \mathrm{~cm}$ a $1 \mathrm{~m}$ de altura y $40 \mathrm{~cm}$ de diámetro) incrustados en el área de entrenamiento, es utilizado por los boxeadores mei, pero también por otros sistemas. Los boxeadores ejecutan sus posturas y transiciones sobre los postes 0 entre ellos. En cualquier caso, debido al lugar central de la flor del ciruelo en la iconografía confuciana, la asociación de dicha flor con diversas formas, estilos y tipos de aparatos de entrenamiento de boxeo chino no ha de resultarnos sorprendente.
EJECUCIÓN DE MOVIMIENTO SOBRE LOS PILARES DE LA FLOR DEL CIRUELO.

Cortesía de Sang Quanxi. 


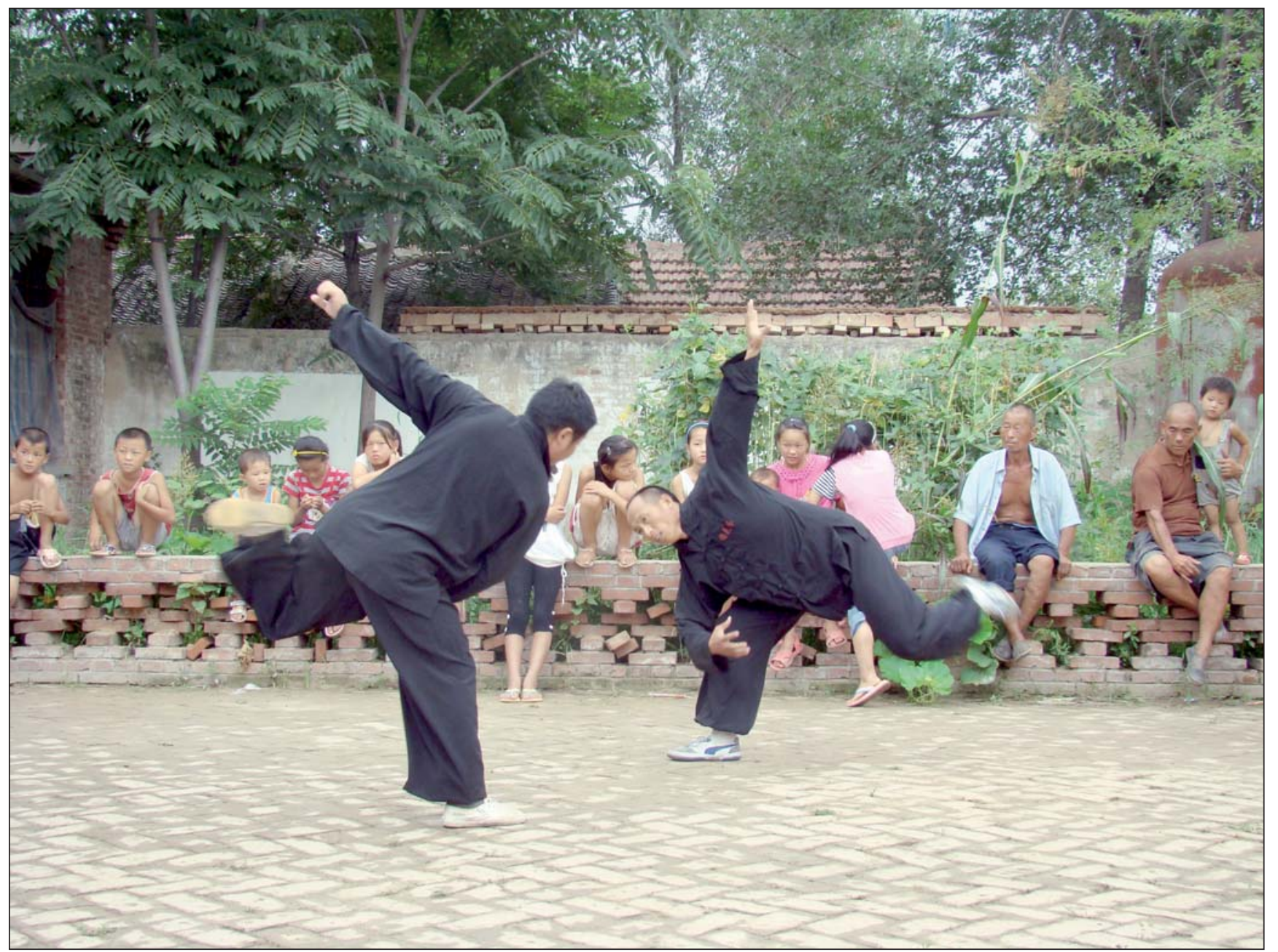

Sin embargo, el meihuaquan no es puramente, ni siquiera principalmente, confuciano. Las deidades taoístas ocupan un lugar central en las prácticas rituales de los boxeadores. Las posturas del arte se basan en la teoría de los cinco elementos (madera, agua, metal, fuego y tierra), y el símbolo taiji, representativo del principio de los supuestos complementarios (yin-yang), se utiliza para caracterizar las transiciones entre las posturas y el movimiento de la energía que comunica los niveles más altos del arte. En muchos sentidos, el boxeo mei supone un corte transversal de la cosmología tradicional china.

\section{Método}

Las informaciones que siguen se basan en gran medida en el trabajo de campo realizado por Zhang Guodong y Li Yun entre los años 2007 y 2010, en aproximadamente 30 pueblos de las provincias de Shandong, Henan y Hebei. Los datos fueron recogidos mediante entrevistas ${ }^{1}$ y observaciones participantes.

${ }^{1}$ Como punto de partida, Zhang utilizó en sus entrevistas la siguiente lista de preguntas: 1) ¿Qué edad tiene usted? ¿Durante cuantos años ha estado usted aprendiendo boxeo mei?; 2) ¿Puede usted hablar sobre su familia?; 3) ¿Puede usted hablar sobre su experiencia en el aprendizaje del meihuaquan?; 4) ¿Puede usted hablar sobre sus relaciones como aprendiz?; 5) ¿Puede usted hablar sobre la historia del meihuaquan en su pueblo?; 6) Por favor, relate algunas historias sobre

LUGAR PARA LA PRÁCTICA DEL BOXEO EN EL PUEBLO ZHU ZHAI, PUYANG, PROVINCIA DE HENAN. 
Los antecedentes de Zhang como discípulo del boxeo de la flor del ciruelo de 16a generación con el maestro Sang Quanxi de Heze (suroeste de la provincia de Shandong) proporcionaron informaciones adicionales para el presente artículo. Aunque el estatus de Zhang como "interno" ha facilitado la ejecución de este proyecto, la buena práctica del trabajo de campo dicta que los investigadores han de tener cuidado para evitar omisiones e ideas preconcebidas que puedan llevar a conclusiones tendenciosas. Por tanto, uno de los papeles de Green y Li Yun ha sido ofrecer el equilibrio que pueden proporcionar los analistas y observadores ajenos al arte.

Zhang Guodong nació a finales de la década de 1970 en la campiña de Heze, donde se ha documentado una fuerte tradición cultural en la práctica de artes marciales desde al menos mediados del s. XVII a.C. De hecho, casi todos los pueblos de la zona tienen un lugar para la práctica del boxeo.

Tanto los padres paternos como maternos de Zhang, así como sus tíos, son artistas marciales. Las influencias familiares, la tradición local y los medios de comunicación dieron pie a que Zhang se interesase de forma continuada por las artes marciales durante la década de 1980. Durante este período, Zhang pasó mucho tiempo en el lugar de práctica de boxeo de su pueblo, y allí comenzó a aprender boxeo de la flor del ciruelo, boxeo Shaolin y boxeo Hong. En 1997 ingresó en la Universidad de Heze y de manera simultánea comenzó su entrenamiento académico en educación física con el profesor Sang Quanxi, un heredero de 15a generación del boxeo de la flor del ciruelo. Un año más tarde Zhang, junto a 15 compañeros de clase, fue iniciado ceremonialmente como discípulo de Sang. La investigación de Zhang se ha beneficiado de los lazos de linaje de su maestro en $\mathrm{Heze}^{2}$. Al entrar en la escuela de posgraduado en la Universidad de Southwest (Chongqing, China), Zhang comenzó a centrarse en la investigación de la cultura de las artes marciales basada en trabajos de campo con la guía de su profesor tutor Dpal-Idan-nyi-ma. Como resultado, en el 2007 Zhang comenzó la investigación de campo sobre el boxeo de la flor de ciruelo en su localidad natal de Heze, y posteriormente extendió su investigación a las provincias vecinas.

En su localidad natal, Zhang ya conocía a muchos de los maestros ancianos del boxeo de la flor del ciruelo, en las fases iniciales de su investigación en 2007-2008. El aprendizaje de Zhang con el maestro Sang reforzó su estatus como discípulo en la comunidad global de boxeo, permitiéndole obtener permiso para entrevistar, fotografiar y participar en clases conducidas por otros maestros. Una

maestros de meihuaquan con los que esté familiarizado; 7) Por favor, relate alguna actividad de liangquan que le haya impresionado especialmente; 8) ¿Cómo se procuró usted a sus aprendices?; 9) ¿Qué dificultades atraviesa actualmente el meihuaquan de su localidad?; 10) ¿Qué piensa usted sobre el desarrollo futuro del meihuaquan en su localidad?

2 El maestro de Sang fue W ang Peilian, una influyente figura de Heze en la guerra Chino-Japonesa. W ang estudió en la 6a Escuela Provincial de Shandong (1928-1931), y en 1934 ingresó en la Universidad Militar Central de W hampoa (Partido Nacionalista de la Academia de Oficiales del Ejército Chino), en Nanjing. Fue comandante de compañía y comandante de batallón y participó en la Ofensiva de los Cien Regimientos en la guerra Chino-Japonesa. El maestro de W ang, Gao Yuting (Bitang), fue un respetado artista marcial de la 6a Escuela Provincial de Shandong. La localidad natal de Gao es el pueblo de Zhu, en la localidad de Liyuan, Puyang (provincia de Henan), que es una de las cunas del boxeo de la flor del ciruelo. 
fuente fundamental de información ha sido el ya citado Wu Baihua, uno de los más famosos maestros ancianos de Heze $\mathrm{e}^{3}$. Cuando su grupo practica en el lugar de entrenamiento cada mañana, a menudo relatan historias sobre el boxeo de la flor del ciruelo. La implicación de Zhang, tanto en las instrucciones formales como en las sesiones menos formales de narración de historias, son muestra de su aceptación en el círculo interno del grupo de W u. Como consecuencia, W u presentó a Zhang a su estudiante Cao Guangchao, un profesor de enseñanza secundaria. Cao tiene aproximadamente 35 años de edad y acumula una experiencia de 18 años como maestro. En compañía de Cao, Zhang visitó muchos lugares de entrenamiento, a antiguos maestros y jóvenes aprendices, y observó varios rituales de aprendices de los grupos, el culto activo a los patriarcas de los grupos y demostraciones públicas de boxeo en las provincias de Shandong, Henan y Hebei.

El profesor Sang proporcionó un continuo apoyo durante el trabajo de campo. Por ejemplo, durante el verano de 2009, Sang y Zhang fueron al pueblo de Zhu, de la localidad de Liyuan (Puyang), para rendir culto a los patriarcas locales del boxeo. Junto a la gente del lugar, ambos mostraron su respeto (lo que significa rendir homenaje poniéndose de rodillas e inclinándose hasta tocar con la frente en el suelo) a los patriarcas, y tomaron parte en las exhibiciones formales de boxeo. Este tipo de observación participante en diversas localidades ha resultado útil para llegar a comprender la cultura local de las artes marciales. Durante el verano de 2010, Zhang se desplazó de nuevo al pueblo de Zhu, siendo calurosamente acogido.

Además de lo expuesto, también se ha recogido información adicional de practicantes del estilo y de otros estilos durante los tres años del trabajo de campo por vía telefónica, correo electrónico, chats o cartas.

\section{Entorno histórico, geográfico y social}

El boxeo de la flor del ciruelo se originó en el norte de la provincia de Jiangsu, en la costa este de China, se difundió por toda la provincia y finalmente al oeste hacia las provincias de Anhui y Henan y al norte hacia las provincias de Hebei y Shandong (Lu Yao \& Yan Zijie, 1990). Desde la época del emperador Kangxi (1661-1722 d.C.), estas provincias han sido el núcleo para el desarrollo del boxeo de la flor del ciruelo, particularmente entre el grupo étnico mayoritario de los Han. Son dos los factores que han predispuesto a que en esta zona se hayan desarrollado las habilidades marciales: un rudo entorno que ha hecho difícil el ganarse la vida y los consiguientes desórdenes en el ámbito social.

A lo largo de las fronteras de las provincias de Jiangsu, Shandong, Anhui, Henan y Hebei, donde el meihuaquan es popular, el suelo y el clima no son favorables para la agricultura. El $60 \%$ de la lluvia cae entre junio y agosto, cuando las temperaturas ascienden a $24-28^{\circ} \mathrm{C}$. En invierno, el clima es frío (medias entre -5 y ${ }^{\circ} \mathrm{C}$ ) y seco. La desigual distribución de las precipitaciones provoca frecuentes sequías en primavera e inundaciones en verano en las planicies del noroeste.

3 El hermano de su abuelo, W u Tipan, fue instructor de artes marciales en el Kuomintang (KMT, el Partido Nacionalista Chino). Inició el boxeo de la flor del ciruelo en Taiwán después de trasladarse allí siguiendo a Chiang Kai-shek (cabeza del KMT entre 1925 y 1975). 
El contenido alcalino del agua es significativo, lo que provoca una importante alcalinización del suelo. Estos aspectos dificultan la agricultura en la zona.

La planicie Huanghuaihai, la planicie norte de China, es una planicie aluvial a lo largo de los canales de tres ríos: el río Huang, conocido comúnmente fuera de China como Río Amarillo, el Huai y el Hai. Ha sido una zona densamente poblada desde principios de la dinastía Qin (221-206 a.C.), con las mayores concentraciones de habitantes en Shandong, Henan y Hebei, el centro de las tradiciones marciales. El cultivo intensivo que hicieron posible los sistemas de riego determinó la densidad poblacional de la zona. La densa población proporcionó suficiente trabajo para las laboriosas temporadas de plantación y cosecha. No obstante, esto creó un excedente de activos laborales durante los 2/3 restantes del año. Históricamente esto ha dado como resultado la deficiente economía del Shandong occidental.

Actualmente, en otras partes de Shandong, el excedente de trabajadores puede encontrar empleo para corregir las deficiencias de la agricultura y mantener la salud de la economía provincial. Sin embargo, antes de finales del s. XVIII, la agricultura proporcionaba el único medio de vida disponible para los habitantes de la planicie central. Incluso después del surgimiento del sistema ferroviario y de la diversificación comercial en la década de 1930, aproximadamente el 90-95\% de la población se dedicaba a la agricultura. La industria manufacturera, el comercio, la organización y los transportes, que se habían desarrollado en el período de Primavera y Otoño (770-476 a.C.) y en el período de los Reinos Combatientes (475-221 a.C.), no influyeron en las zonas del suroeste y noroeste.

Un factor principal en la cultura económica, social y cultural de la región ha sido la ruptura de los diques a lo largo del Río Amarillo por la acción de devastadoras inundaciones. De acuerdo con las gruesas estadísticas, hasta la década de 1950 los registros históricos indican que los diques se rompieron 1.500 veces y que se realizaron entre 20 y 30 grandes reconducciones (cambios en el curso del río). Estos hechos tuvieron un inmenso impacto social y geográfico en la planicie Huanghuaihai. El desbordado Río Amarillo generó inestabilidad social, lo que creó un hábitat para bandidos, vagabundos y otras figuras que vivían en los márgenes de la sociedad y la justicia - los elementos "desclasados" de la sociedad, como los etiquetó Mao Zedong (Hobsbawm, 1969: 91)-. Bajo la amenaza de estas turbulencias, las personas aprendieron artes marciales con el propósito específico de desarrollar habilidades para la autoprotección. A finales de la dinastía Ming (1368-1644 d.C.), el Río Amarillo se desbordó en la frontera de Jiangsu, Shandong y Anhui. Las inundaciones, en alternancia con las sequías, provocaron fallos y otros desastres naturales, y esto fue el caldo de cultivo de desórdenes sociales que coincidieron con el surgimiento del boxeo de la flor del ciruelo en la zona, y probablemente contribuyeron a su desarrollo.

La rampante anarquía de la región promovió habilidades marciales altamente desarrolladas a ambos lados de la ley: entre aquellos que deseaban protegerse frente a los bandidos y entre los propios criminales. A medida que los desastres naturales, especialmente las inundaciones del Río Amarillo, ensanchaban la brecha entre ricos y pobres, algunos campesinos eligieron el riesgo de convertirse en bandidos para que tanto ellos como sus familias pudiesen sobrevivir. El accidentado 
paisaje de las fronteras entre las provincias de Jiangsu, Shandong, Henan y Hebei facilitó que los campesinos bandidos se escapasen de la persecución de las fuerzas gubernamentales; mientras tanto, aquellos que poseían tierras u otros activos se encontraron ante la necesidad de crear fuerzas privadas y consolidar su poder a fin de defenderse. En esta situación, el gobierno central estaba impotente. El historiador Joseph Esherick escribe: "Era una sociedad altamente militarizada que había aprendido a defenderse por ella misma" (1987: 20). De hecho, podemos especular que la conversión al bandolerismo en estas circunstancias sociales y en esta área es una honrosa estrategia. Eric Hobsbawm llega al punto de calificar a esta zona como representativa de las "áreas de bandidos" (1987: 17). Además, las reiteradas insurrecciones a gran escala endémicas de la zona suponen una evidencia convincente de que a medida que un mayor número de campesinos se hallaba bajo la presión de la supervivencia, estos escogían la rebelión a gran escala más que transformarse en bandidos de bandas de tres o cuatro miembros. Eventos sociales y naturales similares provocaron la Rebelión de los Turbantes Amarillos (184 d.C.) durante el declive de la dinastía Han del Este (22-220 d.C.), y la de los Turbantes Rojos durante las décadas de declive de la dinastía Yuan (1271-1368 d.C.).

Por tanto, la intensificación periódica de los conflictos sociales -generalmente a finales de cada dinastía, basados históricamente en diferencias de clase, economía y origen étnico- promovió más aún el desarrollo de las artes marciales tradicionales en la región. Como el historiador militar C.J. Peers señaló respecto a China, "Las sucesivas dinastías surgieron y unificaron el país... Con el tiempo [un deterioro de la virtud condujo a ello] al colapso de la autoridad central. Seguiría un periodo de fragmentación y caos" (2006: 8). Hasta mediados del s. XX, la sociedad china seguía estratificada en terratenientes (la clase gobernante que gobernaba en virtud de la propiedad de la tierra) y los campesinos (agricultores arrendatarios). En la planicie central, el conflicto entre los campesinos y los señores de las tierras corría por toda la sociedad y cambiaba en intensidad y medios de expresión relativos al grado de explotación percibido por la clase campesina. "En general, las explotadoras tasas sobre la tierra que imponían los poderosos se mantenían justo hasta el punto que permitían a los campesinos vivir con estrecheces... Los desacuerdos entre ellos permanecían en el moderado estado de un compromiso mutuo. Sin embargo, una vez la represión y explotación de un país por aquellos que poseen las tierras se convierte en intolerable, los campesinos se verán forzados a levantarse públicamente para forzar a la clase gobernante a ajustar algunos vínculos de las relaciones de producción, hasta que las órdenes gubernamentales vuelvan a la normalidad" (Shi \& Hou, 1992: 148).

Históricamente, más de la mitad de las famosas revueltas campesinas en la historia china se han originado en las planicies del norte, y la mayoría fueron como resultado de la intensificación de los conflictos sociales señalados anteriormente. Por ejemplo, el movimiento Bóxer, a finales de la dinastía Qing (1644-1912) surgió en la provincia de Shandong, puesto que la Sociedad Recta y Armoniosa - Yihétuán- (Esherick, 1987: 154) y las historias tradicionales sostienen que la fuerza principal se componía primariamente de boxeadores de la flor del 
ciruelo4. La Rebelión Bóxer fue una respuesta al estrés social generado por múltiples factores: externos (expansión de las naciones imperiales de Francia, Japón, Rusia y Alemania, las manipulaciones económicas de Inglaterra y de los Estados Unidos, y el evangelismo cristiano), internas (la "Reforma de los Cien Días", un movimiento imperial para modernizar China) y los desastres naturales (una severa sequía seguida de devastadoras inundaciones que arrancaron a los agricultores de la provincia de Shandong y les forzaron a abandonar sus hogares). Esta alteración sucedió en los últimos años de la dinastía Qing, a finales del s. XIX. Entonces, al igual que en el final de todas las dinastías chinas, como sugiere Peers, los agricultores dieron un paso en el camino de la resistencia con el objeto de sobrevivir. La práctica de las artes marciales fue, meramente, uno de los métodos y formas de aproximación elegidos para lograr tal fin.

\section{Cultura tradicional y sociedades religiosas}

El corazón de la planicie septentrional china es una región de antiguas convergencias culturales. Allí, los trabajadores agrícolas, los señores de las tierras y los habitantes urbanos se mezclaban y contribuían a una rica y diversa cultura tradicional. En los repertorios de estas culturas tradicionales, las leyendas de héroes, los cuentos de caballería y las óperas épicas creadas en torno a la fama de antiguos generales crearon unos sólidos cimientos para las tradiciones marciales. Además, las artes marciales y la fe coexistieron en varias religiones practicadas por los civiles.

El drama folclórico y la ópera popular florecieron en las provincias de Hebei, Shandong y Henan, donde estas formas teatrales constituían un medio de entretenimiento fundamental para los lugareños en la China tradicional. Diariamente, los aldeanos se juntaban en la calle para escuchar las narraciones de cuentos (Esherick 1987: 222). Los temas más populares de estas narrativas se centran en antiguos emperadores, héroes caballerescos, oficiales justos y honestos y situaciones históricas en las que prevaleció la justicia y la caballerosidad. Con carácter más notable, Liangshan (montaña Liang), en la provincia de Shandong, fue la fortaleza de los 108 héroes tradicionales popularizados en la novela clásica china Shuĭhǔ Zhuàn (Crónicas del Pantano, también conocida como Margen del Agua, Todos los Hombres son Hermanos, y Héroes del Pantano). Estas historias expresaban un concepto de la justicia tradicional en el cual "las personas no se

\footnotetext{
4 Los detalles históricos sustancian el papel esencial de los boxeadores mei en la Rebelión Bóxer. La resistencia a la influencia occidental en el área de Liyuantun de Shandong a finales del s. XX fue dirigida por un grupo campesino conocido como "Los 18 Jefes". Su líder Yan Shuqin era experto en hongquan. Sobre 1892, Yan pidió el apoyo de los boxeadores de la flor del ciruelo de Zhao Sanduo, del pueblo de Shaliuzhai. Los boxeadores de la flor del ciruelo tienen una larga historia en la zona, y Zhao particularmente fue conocido por su fuerte sentido de la justicia. Como resultado del carácter de su líder, la reputación de estos boxeadores era más la de protectores que la de depredadores. Como reacción ante la apropiación de un templo local en Liyuantun por los cristianos, en abril de 1897, los boxeadores de la flor del ciruelo realizaron una demostración de liangquan de tres días en Liyuantun como muestra de fuerza. Aunque no fue abiertamente anti-cristiana, incitó al ataque de un templo dedicado al Emperador de Jade (la mayor deidad taoísta) que había sido convertido en Iglesia por los cristianos. Este evento fue visto como uno de los precursores de la Rebelión Bóxer (Cohen, 1997: 23-25).
} 
fijaban en la justicia, sino que confiaban en el poder real y la espada imperial, la ejecución de villanos por oficiales íntegros y la eliminación de la injusticia" (Hsu, 2006b: 304). De este modo, las actitudes engendradas por la cultura tradicional reforzaban la popularidad de las artes marciales en la región. De hecho, en su análisis del movimiento Bóxer de finales del periodo Qing, Esherick afirma que los bóxers extrajeron su inspiración fundamentalmente de "las historias dramáticas de la ópera local" (1987: 39).

China tradicionalmente ha auspiciado organizaciones, a menudo sociedades secretas, basadas en comunidades geográficas y religiosas. Históricamente, estas organizaciones funcionaban para fortalecer la identidad social particular del grupo, e impulsaban la resistencia ante el gobierno y otras élites a través de la práctica de rituales diseñados para realzar el valor marcial mediante medios sobrenaturales. A lo largo de las dinastías Ming y Q ing, la ópera, las artes marciales, el acrobatismo, el chamanismo y otros elementos de la cultura vernácula se integraron en los rituales religiosos que servían como poderosas herramientas para unir a los individuos en coaliciones para la rebelión social (Esherick, 1987: 62-66). Las diversas encarnaciones de la Secta del Loto Blanco (dinastías Song a Qing), los bóxers (dinastía Q ing), y la Asociación de las Lanzas Rojas (de principios o mediados del s. XX) representan tales organizaciones. La combinación de artes marciales y religiones vernáculas proporcionaban la fuerte autoprotección deseada por la gente corriente en una sociedad caótica.

\section{El "carácter" de la flor del ciruelo}

Filosóficamente, el boxeo de la flor del ciruelo traduce "caracteres de personalidad" específicos de la flor del ciruelo a la teoría y práctica del boxeo. El ciruelo florece cuando hace frío y es la primera flor que aparece en la primavera. Por tanto, su vigorosa constitución ha llevado a que el ciruelo se haya empleado como símbolo de la personalidad ética y distante que se esfuerza por autosuperarse, nutriendo el desarrollo espiritual. De este modo, se enseña a los estudiantes del boxeo tradicional de la flor del ciruelo que deben perseverar bajo condiciones austeras, en comparación con aquellos estudiantes de artes marciales con un enfoque más moderno.

La región fronteriza de las provincias de Anhui, Henan, Hebei, Jiangsu y Shandong tiene una larga tradición en la formación de redes sociales basadas en relaciones familiares, y se han desarrollado grupos de artes marciales de acuerdo al mismo principio. En la estructura social tradicional china, el parentesco es la base de todas las relaciones y la agricultura intensiva que supone el medio de vida para la mayor parte de la población en la planicie Huanghuaihai promovió otras conexiones. "Los vecinos tienden a convertirse en familia después de vivir juntos durante mucho tiempo, lo que supone otra estrecha conexión sobre la base de afinidades [de subsistencia]" más allá de los lazos de parentesco de sangre (Hsu, 2006b: 15). Como escribe el antropólogo Fei Xiao-tong (2009: 116), esta estructura social es como una tela de araña, donde las relaciones sociales en China funcionan a través de redes de relaciones personales desde el individuo, que está en el centro, con lazos cada vez menos fuertes a medida que uno se mueve hacia la periferia de la tela de araña. De este modo, en la zona que consideramos en 


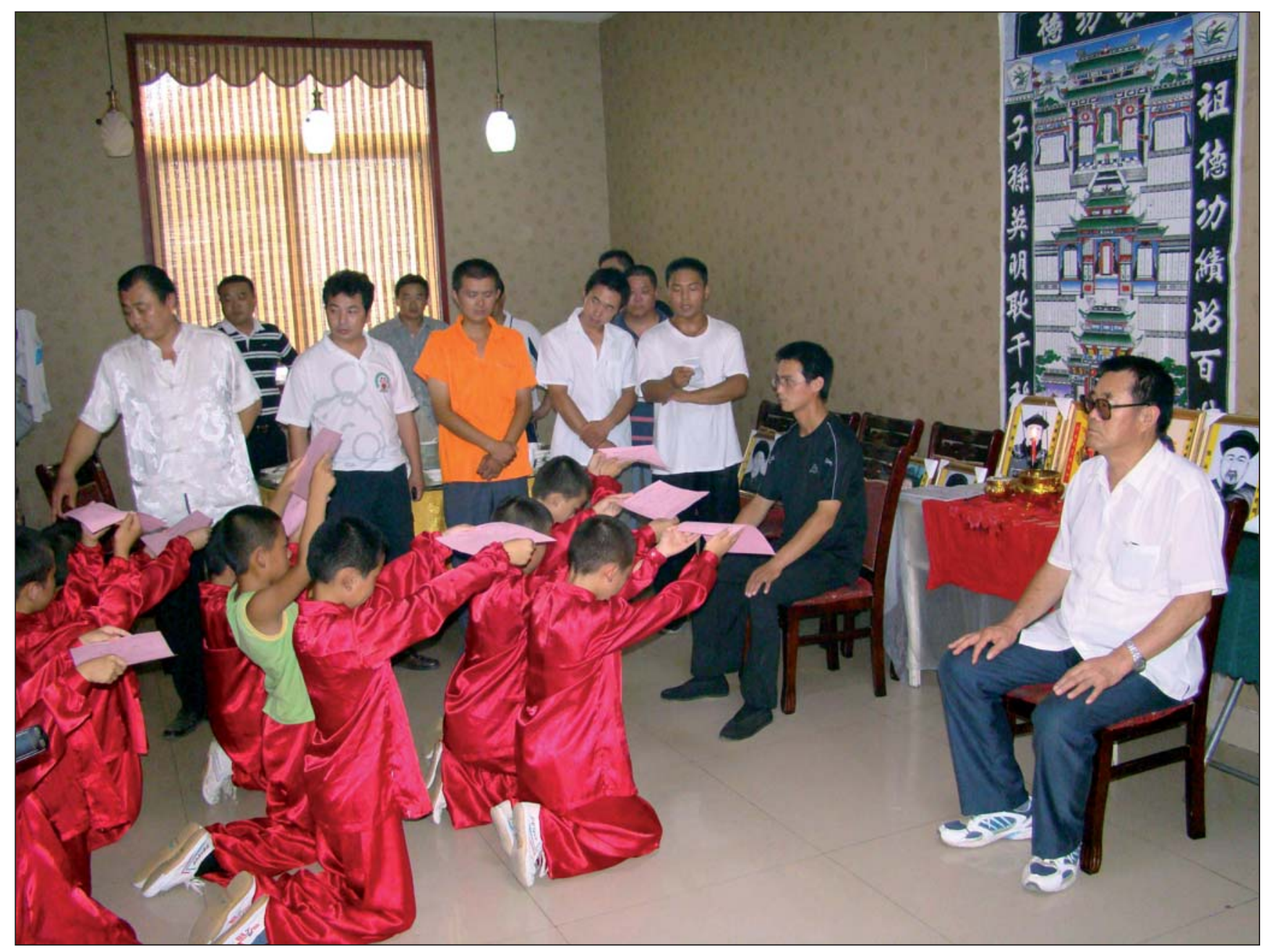

Cao Guanchao recibiendo LOS HONORES DE SUS NUEVOS APREN DICES,

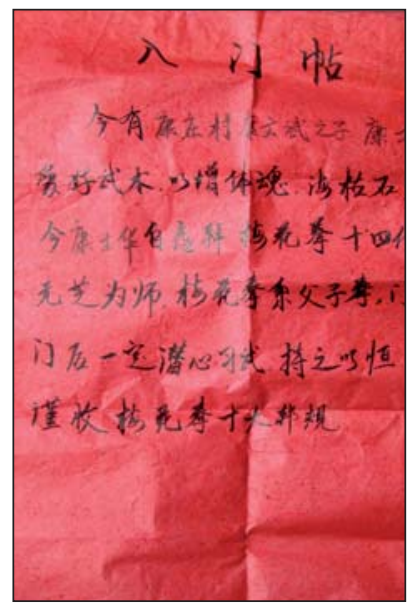

Certificado de RELACIÓN ENTRE MAESTRO Y APRENDIZ. este estudio, varios grupos y clases desarrollaron sus espacios sociales modelándose ellos mismos a partir de las relaciones genéticas, que se manifiestan en los profundamente enraizados lazos de identidad del clan, y por supuesto el grupo marcial no es una excepción. Aunque la mayoría de maestros de artes marciales y aprendices no tienen relación de sangre, se identifican como una única familia (Hsu, 2006b: 22).

Tradicionalmente, la relación entre el maestro de artes marciales y el aprendiz se caracteriza por ser como el lazo de sangre entre un padre y un hijo, aunque los maestros contemporáneos también aceptan mujeres como estudiantes ${ }^{5}$. El maestro tiene una autoridad absoluta sobre el aprendiz y el aprendiz venera al patriarca (el fundador) del sistema como si fuese un ancestro. El meihuaquan no es una excepción a esta regla general.

W u Baihua, un maestro del boxeo de la flor del ciruelo de 70 años que reside en Heze, comenta, "Cuando yo era niño vivía con mi maestro. Le ayudaba

5 El meihuaquan no restringe a las participantes femeninas, aunque el estatus de las mujeres es más bajo que el de los hombres en las zonas rurales de la China tradicional. Existen muchas mujeres que practican boxeo mei en W angfang. La mujer del nieto de W ang Zhongyun nos contó que se hizo aprendiz del boxeo de la flor del ciruelo cuando se integró en la familia Wang. Tanto el maestro Cao Guangchao como el maestro Sang Quanxi tienen varias mujeres aprendices. 

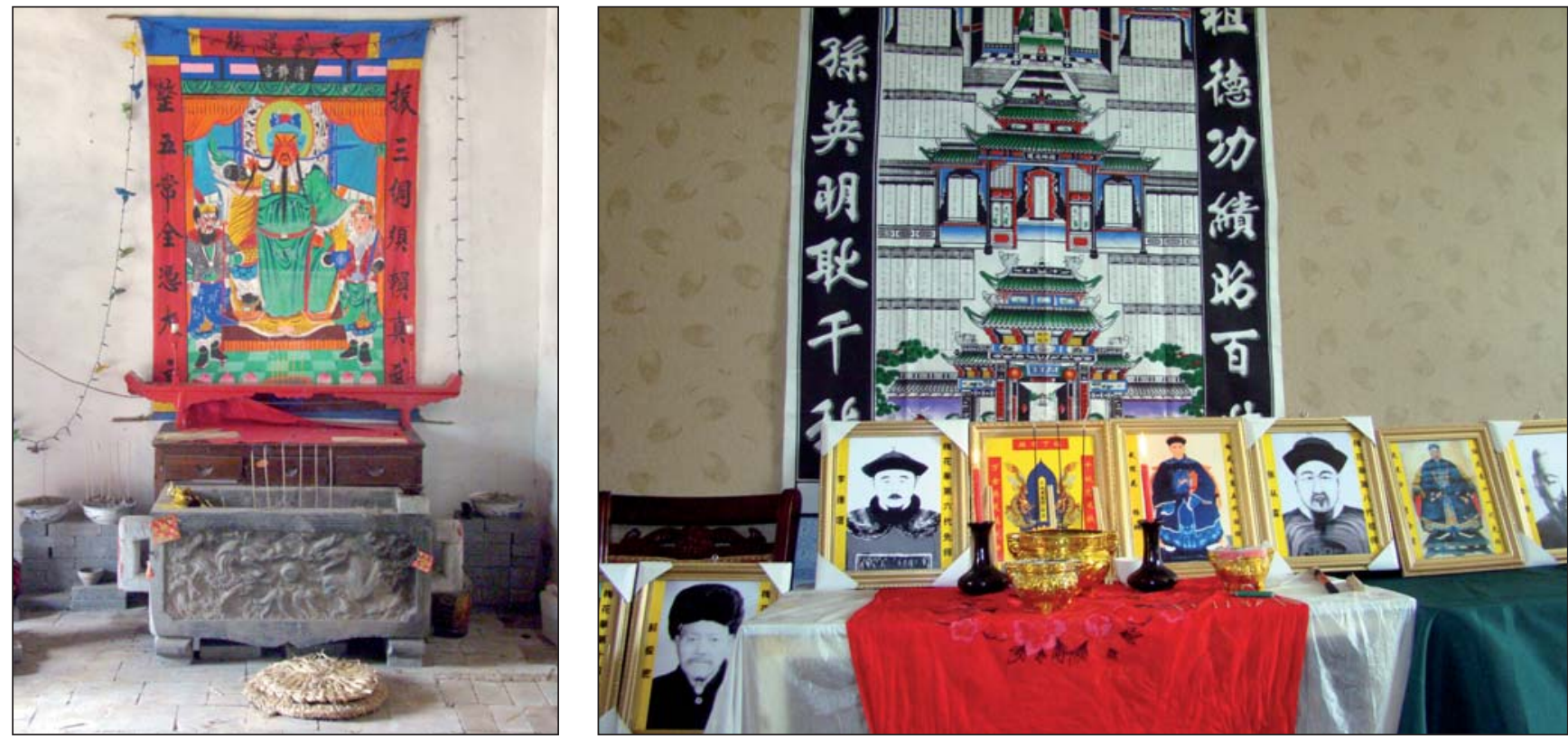

con las labores domésticas durante el día y aprendía boxeo mei por la noche. Era muy estricto conmigo, porque cada vez que cometía un pequeño error o no lo hacía suficientemente bien, me azotaba". La veneración del propio maestro aún está muy difundida en muchas artes marciales vernáculas chinas $(A M V C)^{6}$. En segundo lugar, a pesar de la ausencia de un currículo uniforme supervisado por un consejo de administración y aplicado a todos los estudiantes y profesores, los sistemas de boxeo de la flor del ciruelo emplean una estructura global generalmente aceptada y dictada por la tradición para la adquisición de las habilidades marciales, comenzando por el ritual de aprendizaje mediante el cual se acepta al novicio como estudiante.

El periodo de aprendizaje comienza con un ritual que se designa como "ceremonia de entrada", donde los novicios aspirantes se transforman en miembros simbólicos de la familia de boxeo mei. Tradicionalmente, la "ceremonia de entrada" es el rasgo destacado de las AMVC, durante el cual los aprendices rinden homenaje a la divinidad, los ancestros y al maestro que actúa como líder de la familia. El taoísmo constituye la mayor influencia espiritual del boxeo mei. Por tanto, los boxeadores se dirigen al panteón taoísta y generalmente rinden culto a Chenwu, el "guerrero perfecto" de esta tradición, junto con aquellos ancestros a los que se reconoce una contribución sobresaliente al arte. El día de la ceremonia se muestran tablas que contienen representaciones de Chen-wu y de los ancestros, y el maestro que acepta aprendices invita a su propio maestro, a sus hermanos de boxeo mei y a sus otros discípulos a ser testigos de la iniciación. Como segundo elemento crucial del ritual de entrada, el discípulo debe publicar su juramento y hacerlo público por escrito en papel rojo. Durante la ceremonia, el anfitrión lee las reglas familiares y guía a los aprendices a prestar juramento para expresar la leal-

6 En general, "artes marciales vernáculas" designan tradiciones que satisfacen las necesidades de los grupos locales en que son practicadas y preservadas, más que ser productos de un organismo sancionador externo. Las características precisas de tales artes varían según los diversos contextos culturales.

IZQUIERDA:

IMAGen de Chen-W U eN UNA TABLA DE BOXEO MEl.

DERECHA:

TABLAS DE ANCESTROS DE BOXEO MEI. 


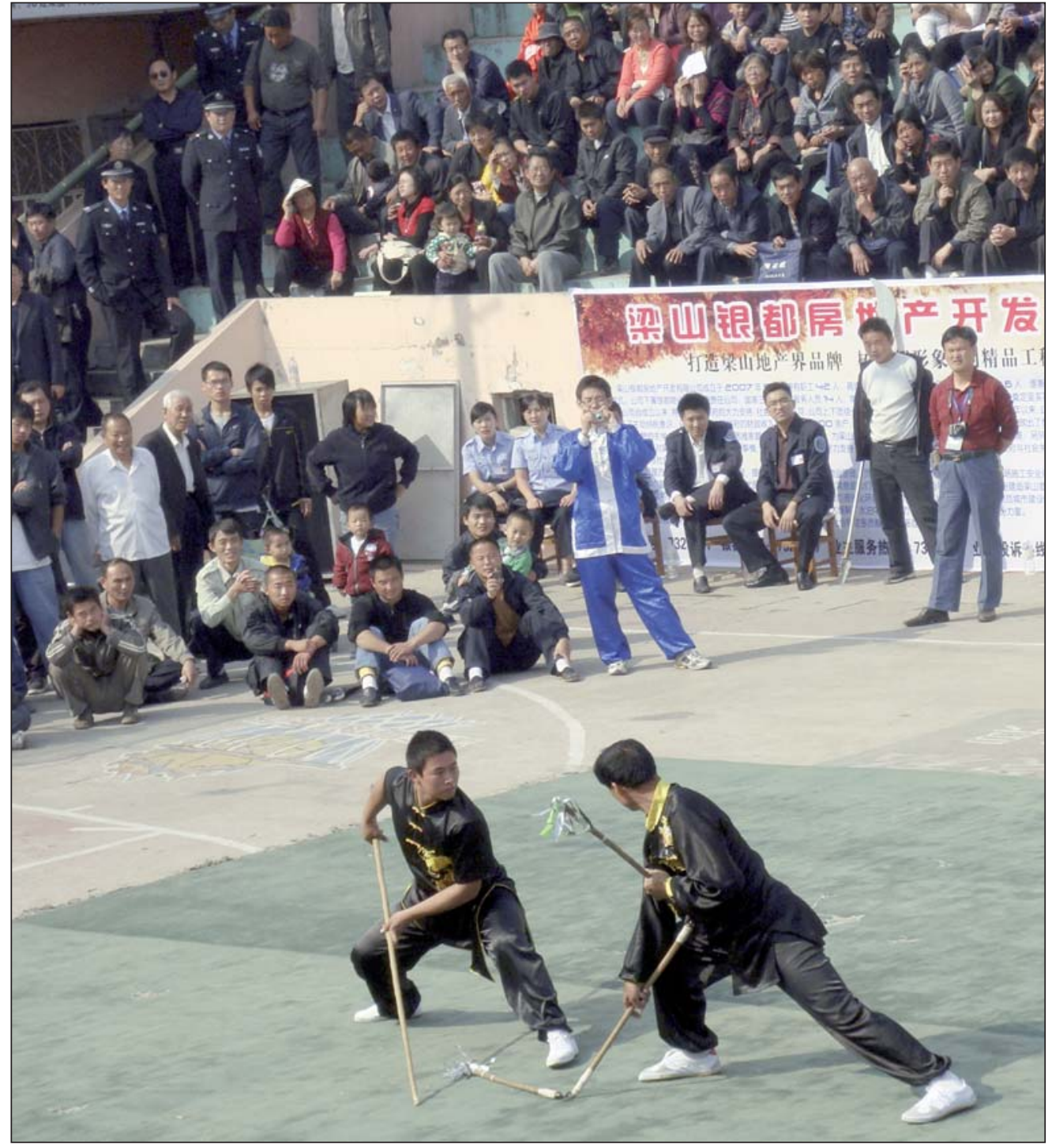

Liangquan, en el Segundo

EVENTO INTERNACIONAL DE LIANGQUAN DE LIANGSHAN, EN 2010.

Cortesía de Sang Quanxi.

Tumba del MAESTRO DE boxeo mel Cal Guangrul.

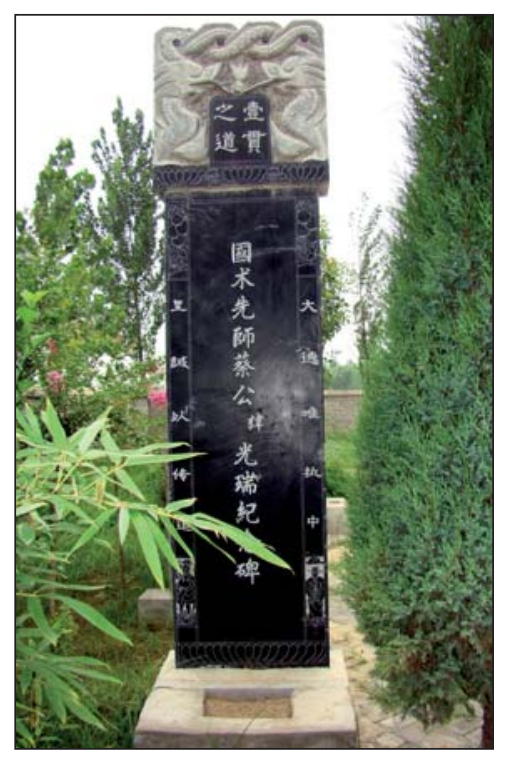

tad a su maestro, a la familia de boxeo mei y al arte del boxeo mei. El tercer y más importante componente de la ceremonia exige que el discípulo se incline nueve veces. Bajo la dirección del anfitrión, el aprendiz debe inclinarse en un correcto orden -tres veces a la divinidad y a los ancestros, tres veces al maestro, tres veces al maestro de su maestro, y finalmente inclinarse tres veces más ante los hermanos y hermanas de la familia-. Entonces, se constituye la relación entre maestro y discípulo.

El ritual de aprendizaje significa que el maestro y el discípulo establecen una relación del mismo tipo de la que prevalece entre un padre y un hijo (o hija). Desde el punto de vista del aprendizaje, los miembros de la familia marcial comienzan a asumir sus correspondientes responsabilidades y obligaciones. El discípulo entra en una familia donde el maestro es el patriarca y puede comunicarse con otros discípulos como miembro de la familia, pero debe acatar las reglas familiares. Únicamente a través del ritual de aprendizaje puede un individuo llegar a ser realmente miembro de la familia, obtener la guía del maestro y recibir el reconocimiento y la ayuda de otros discípulos. El discípulo deja de ser simplemente un individuo, pero se convierte en miembro de un grupo que le ayuda frente a las dificultades sociales, y el maestro se convierte en un miembro más influyente de la 
sociedad a medida que crece el número de sus seguidores. Por tanto, todas las partes en esta relación adquieren un capital social.

La relación establecida mediante este tipo de ritual es muy fuerte. En la cultura tradicional china el acto de arrodillarse e inclinarse es la demostración suprema de respeto, un acto que se ofrece únicamente al cielo, a la tierra, al propio monarca, a los propios parientes y al propio maestro. Al entrar en el periodo de aprendizaje bajo la presencia de una divinidad marcial, de los ancestros y de otros miembros familiares se fortalece la relación tanto a nivel religioso como social.

Tras participar en la ceremonia para honrar al maestro, se permite que el aprendiz comience sus estudios. El aprendiz es iniciado en las técnicas físicas básicas del boxeo mei a través de ejercicios en solitario y rutinas cooperativas, y eventualmente recibe instrucción acerca de los conocimientos teóricos del arte. La instrucción se dirige seriamente. El bromear o negarse a obedecer una orden del maestro o de un hermano mayor está prohibido. "Era tranquilidad lo que envolvía el campo de boxeo, con los jóvenes ejercitándose en el centro. N adie se atrevía a hablar. Pero usted sólo podía encontrar a un hombre anciano sentado en un lado, observando y a veces dando instrucciones y órdenes", recordaba Ma Chao-shuan, del pueblo de Zhu, un heredero del boxeo de la flor del ciruelo, cuando recordaba el escenario de boxeo en el lugar de práctica de su pueblo a finales del s. XX.

El boxeo mei también se caracteriza por una exhibición pública de las habilidades marciales en un evento denominado liangchangzi (literalmente, "demostrar sus artes marciales en un lugar"), en el área de Heze, pero que habitualmente se refiere como liangquan. El evento, realizado durante fiestas importantes tales como el Festival de Linternas anual (celebrado durante el 150 día del primer mes del año lunar del calendario chino, marcando el último día de la celebración del nuevo año lunar chino), reúne a los boxeadores de la flor del ciruelo en el mercado del pueblo 0 en la tumba del patriarca del sistema local. Allí rinden homenaje al patriarca y practican públicamente sus técnicas marciales. Durante estas exhibiciones, los aprendices se afanan por demostrar en público sus niveles más altos de competencia. Como resultado, los no miembros tienen la oportunidad de admirar el boxeo de la flor del ciruelo y el maestro tiene la oportunidad de evaluar a sus aprendices. Los boxeadores mei sostienen que las funciones primarias del evento son el intercambio de habilidades $y$, a través de la demostración de la destreza, expandir la influencia del sistema, de la familia y del maestro que dirige a la familia. Igualmente importante, aunque de un modo menos obvio, los miembros del grupo escenifican su cohesión social, su estatus de élite en la comunidad y su posición cronológica en el linaje del boxeo de la flor del ciruelo.

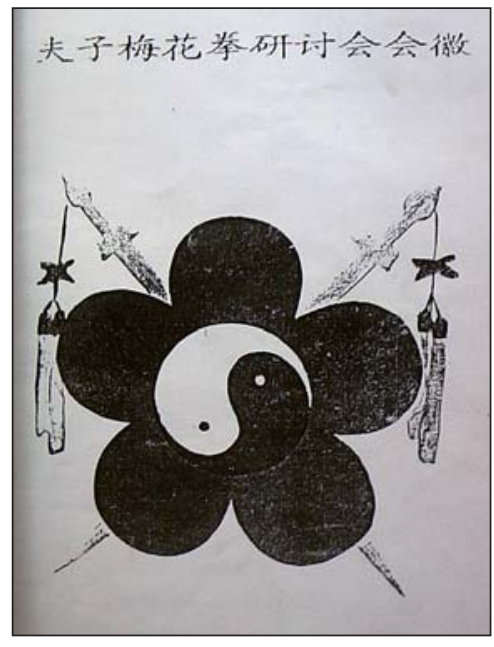

FLOR DE CIRUELO EN UN LIBRO.

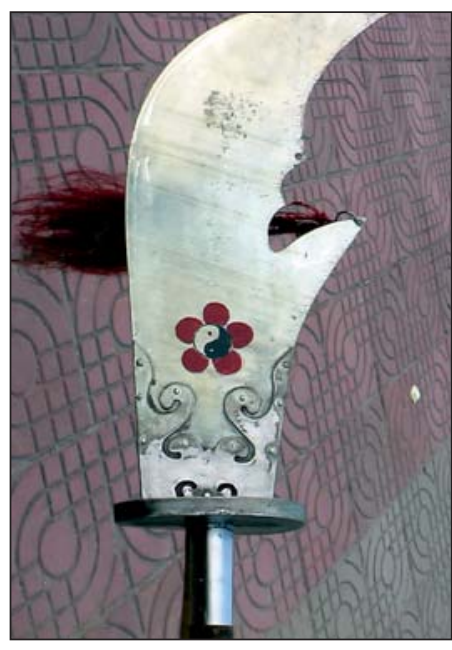

FLoR DEL CIRUELO EN UN GUANDO (ALABARDA). 


\section{La mecánica del meihuaquan}

La flor del ciruelo recuerda a los practicantes no sólo la mentalidad que se exige a los boxeadores de la flor del ciruelo, sino que además sus características físicas sirven como modelo del sistema. Por tanto, la flor del ciruelo es un motivo recurrente en los objetos materiales asociados al arte. El modelo en estos objetos se realiza del modo que muestran las ilustraciones que reproducimos en una alabarda y en un libro (vease página anterior).

Toda flor de ciruelo tiene cinco pétalos. En el boxeo de la flor del ciruelo cada uno de los cinco pétalos representa uno de los cinco elementos: jin (metal), shui (agua), mu (madera), huo (fuego) y tu (tierra). Entre otras cosas, los cinco elementos corresponden a las cinco posturas primarias utilizadas en el sistema: jin bu (postura grande), shui bu (postura suave), mu bu (postura de giro), huo bu (postura pequeña) y tu bu (postura engañosa).

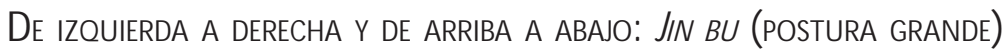
realizada por Cao Guanchao, del pueblo de Heze. Shul bu (postura suave), MU BU (POSTURA DE GIRO), HUO BU (POSTURA PEQUEÑa) Y TU BU (POSTURA engañosa) realizadas por liu Han-jun, del pueblo de Heze.

\section{Cortesía de Cao Guanchao.}
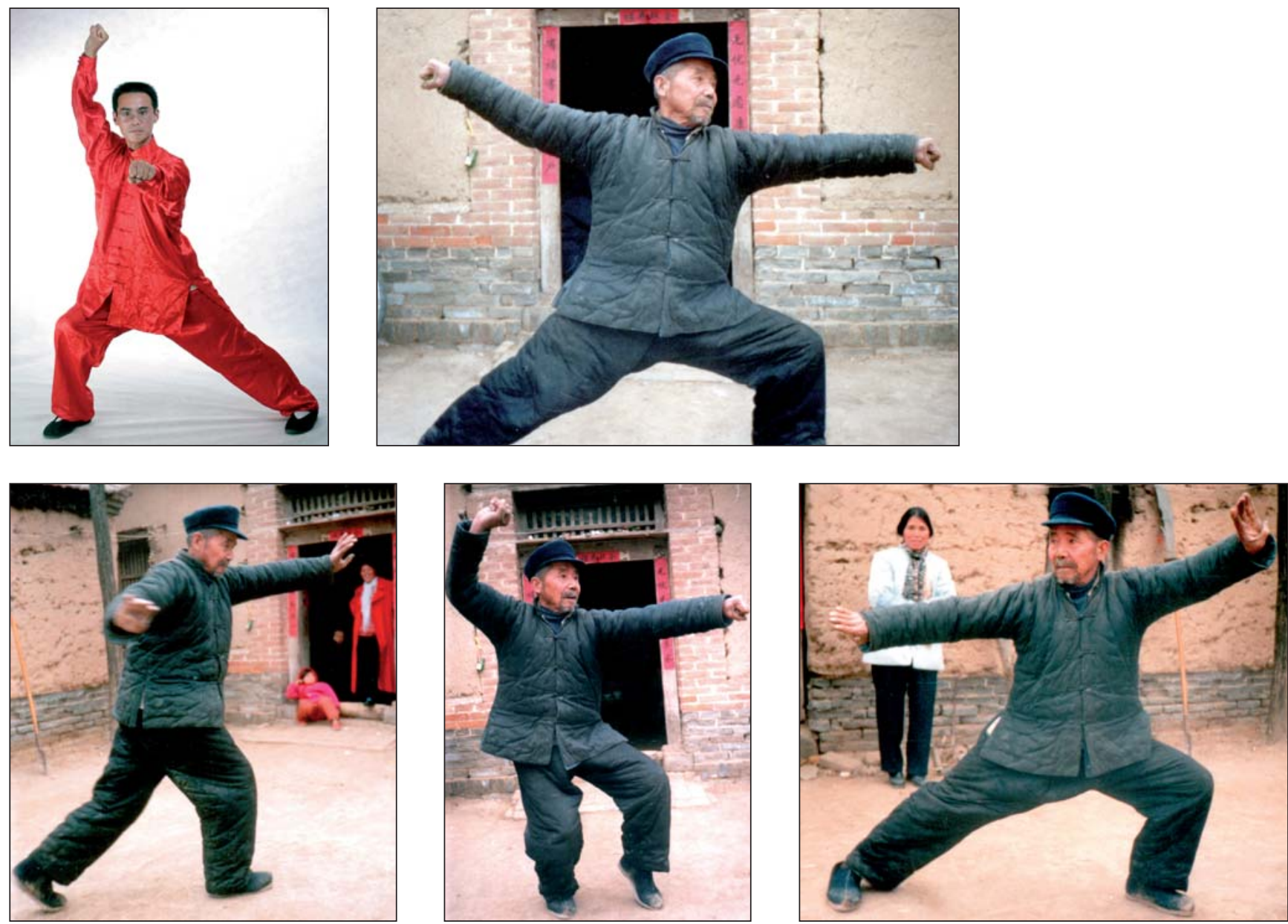
El pistilo, en el centro de la flor del ciruelo, representa el taiji (véanse las imágenes de la flor del ciruelo representadas anteriormente), el símbolo visual de las fuerzas complementarias en las artes marciales, en la vida y en el universo cuya interacción simboliza el cambio perpetuo.

El principio que ilustra esta imagen es frecuente en el pensamiento chino. El concepto emerge no únicamente en el boxeo de la flor del ciruelo, sino también, por nombrar únicamente unas pocas disciplinas, en religión, medicina y adivinación. En el s. III a.C. el filósofo Zou Yan (305-240 a.C.), del estado de Qi (el actual Shandong), unió el principio de la interacción dinámica del yin-yang con los cinco elementos (o cinco fuerzas elementales) del metal, agua, madera, fuego y tierra en una teoría por la cual los fenómenos naturales podían ser comprendidos en términos de resonancias entre estas fuerzas (Sima Qian, Shiji. Traducido al inglés como Records of the Grand Historian).

Los principios mecánicos y estratégicos del boxeo de la flor del ciruelo se derivan de este concepto general del cambio predecible de acuerdo a las relaciones entre los cinco elementos. Las relaciones se exponen a continuación.

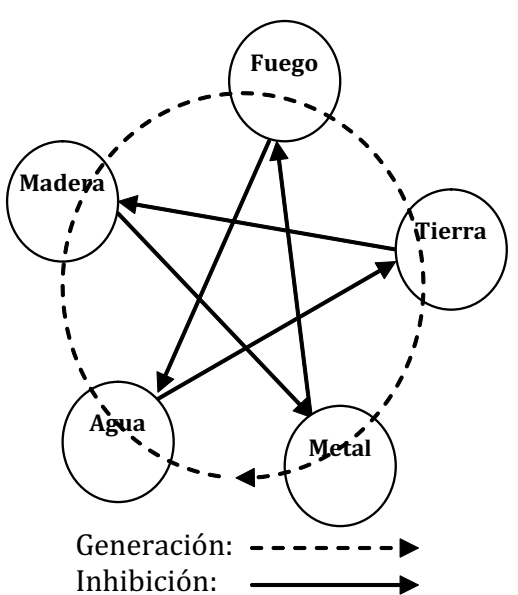

Inhibición:

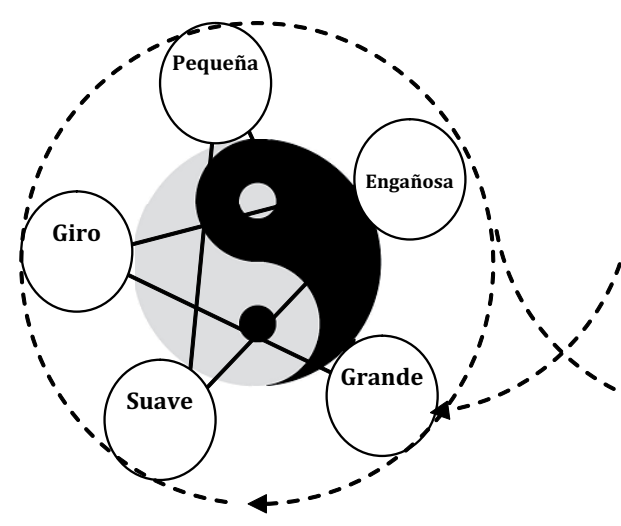

Izquierda

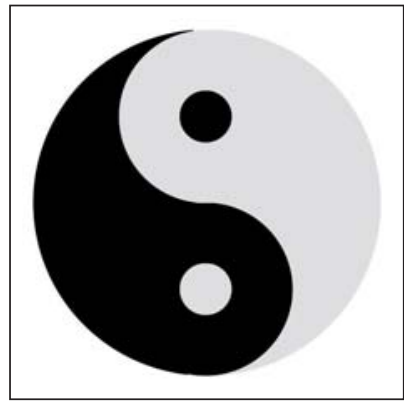

TAlll.

Cortesía de Zhang Guodong.
Estas relaciones se refieren típicamente como el ciclo de generación, representado en la imagen por la línea punteada. En este círculo la madera (mu) alimenta al fuego (huo), el fuego crea la tierra (tu) en forma de ceniza, la tierra produce metal (jin), el metal (un cubo) transporta el agua (shui), y el agua nutre a la madera. Las relaciones antagónicas entre los elementos se conocen como el ciclo de destrucción o ciclo de inhibición. Estas relaciones son las siguientes: la madera parte la tierra (en formas como raíces, palas o estacas), la tierra absorbe el agua, el agua extingue al fuego, el fuego derrite al metal, y el metal (en forma de hacha) trocea la madera. En su traducción al boxeo, esto puede ejemplificarse en una aplicación como que la "postura engañosa" (la postura de la tierra) puede utilizarse para responder a la "postura suave" (la postura del agua), puesto que la tierra absorbe al agua. 
TU BU (POSTURA ENGAÑ OSA), REPRESENTADA en la Rutina de las Cinco

Posturas.

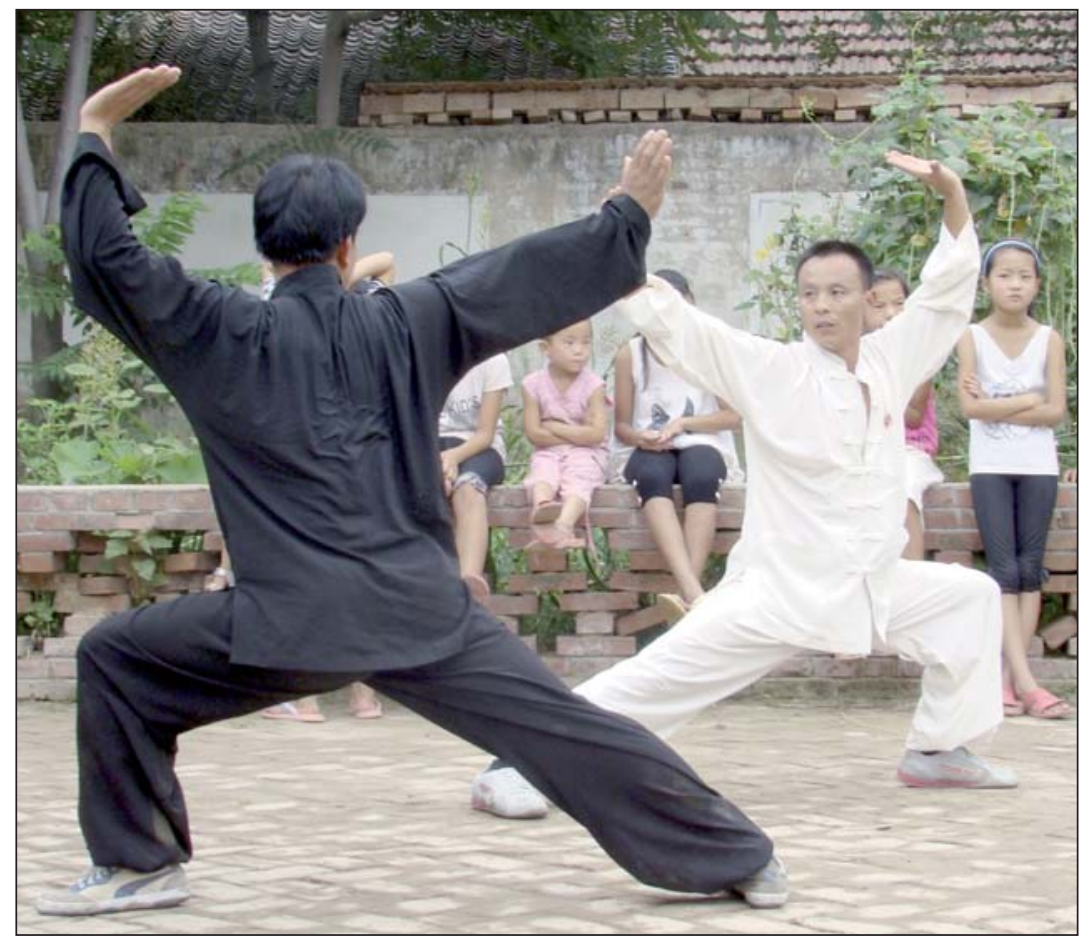

El currículo tradicional del boxeo de la flor del ciruelo puede dividirse en tres niveles progresivos. El primer nivel conlleva la práctica de jiazhi (técnica esencial). Esta práctica se basa en la teoría de los cinco elementos comentada más arriba y en el bagua (los ocho caligramas utilizados para representar los principios complementarios de la cosmología taoísta). En su aplicación práctica en el meihuaquan, las cinco posturas corresponden a los cinco elementos, y cada una de ellas es practicada en sucesión de acuerdo con la secuencia dictada por el círculo de generación e inhibición. Las cinco posturas se realizan en su lugar a la vez que se cambia la posición para orientarse hacia las ocho direcciones del bagua. La práctica de jiazhi también emplea el meiquazhuang (práctica de las cinco posturas en troncos), el ejercicio mencionado anteriormente como los postes o pilares de la flor del ciruelo. Los troncos pueden colocarse según diversas configuraciones: en forma de una flor de ciruelo, en forma del principio del bagua y en la formación jiugong ("nueve palacios", i.e., la disposición de los ocho trigramas del bagua en un modelo en forma de estrella). Las posturas y transiciones se realizan sobre 0 alrededor de los troncos. Los estudiantes deben dominar el jiazhi antes de avanzar al siguiente nivel, para lo que se necesitan de tres a cinco años.

En el nivel intermedio se introduce el combate -consistente en chengquan (técnicas preestablecidas) y combate libre (ningquan)-. El chengquan conlleva rutinas de combate que incluyen agarrar, apresar, golpear con los puños y con las piernas y técnicas de lucha. Estas rutinas encarnan métodos más avanzados de práctica de los principios de la forma (xing), de la respiración (qi) y de la idea (yi) en que se basa el jiazhi. Las técnicas se practican en parejas mientras se encaran las ocho direcciones del bagua (norte, sur, este, oeste, noreste, noroeste, sureste, suroeste). Los compañeros practican las técnicas por turnos. Por ejemplo, la secuencia que se ilustra (al margen) de la "Rutina de las Cinco Posturas" muestra la aplicación de la postura tu de un modo preestablecido.

El ningquan es una versión más avanzada del chengquan, en la que los compañeros se atacan aleatoriamente. Como en el primer nivel, el nivel intermedio también exige de tres a cinco años de práctica antes de que el estudiante esté listo para avanzar al tercer nivel.

En el tercer nivel de entrenamiento se introducen las armas. En este nivel aparece la aplicación avanzada de los conceptos del boxeo mei que fueron adquiridos al dominar las bases del primer nivel. El principio de aplicar formas básicas a la utilización de armas puede apreciarse en las imágenes que presentamos. Al igual que en la Rutina de las Cinco Posturas, en estas imágenes se vuelve a utilizar la postura tu 


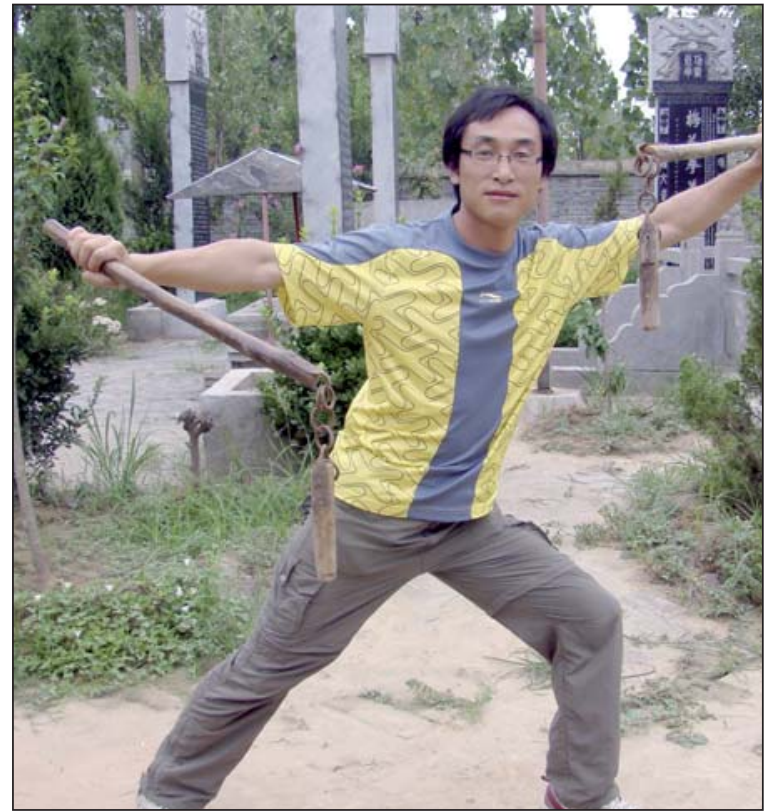

Zhang Guodong practicando la postura ENGAÑOSA CON LOS PALOS LARGOS DE DOS SECCIONES. en una técnica de espada y en una técnica de palo largo de dos secciones. El entrenamiento con armas incluye tanto la práctica en solitario como la práctica con un compañero.

Un rasgo del meihuaquan es la inclusión de una asombrosa colección de antiguas armas raras. Algunas de las más exóticas que continúan siendo empleadas por los boxeadores mei son el yanchitang (una horca de tres puntas colocadas a modo de cola de ganso salvaje), hushenpi (un tipo de armadura con púas), wuhuben (cinco hachas), yibensanqiang (un hacha y tres lanzas), fenghuolun (ruedas de fuego), sijietang (horca de cuatro secciones), y muchos tipos de bastones (shuangguai, un arma similar a un bastón y utilizada de manera muy similar a la tonfa japonesa).

A finales del S. XX un libro titulado El origen del meihuaquan fue descubierto en una zona rural de Hebei. En él se registró la leyenda de "Los tres aprendices llamados De enviados a una misión por su maestro". A finales de la dinastía Ming o principios de la dinastía Qing (aproximadamente de mediados a finales del $\mathrm{S}$. XVII), un famoso maestro de 4a generación Ilamado Cai Guangrui envío a tres de sus aprendices, Li Jin-de, Zheng Yu-de y Xu Jin-de a la ciudad de Xushou en la provincia de Jiangsu para invitar a su maestro Zou Hongyi a que regresase a Hebei para enseñar boxeo mei. Zou fue el primer maestro que difundió abiertamente el meihuaquan?7. El maestro Zou y los tres De regresaron con una carretilla, que estaba construida a partir de muchos tipos de armas antiguas y raras ${ }^{8}$. Debido al gran número y variedad de armas existentes en el repertorio del boxeo mei, este nivel también exige de tres a cinco años para su dominio.

Los tres niveles son complementarios y constituyen un sistema completo de entrenamiento del meihuaquan. Pero el jiazhi, el método de entrenamiento básico, ha de practicarse en todos los niveles. En el nivel avanzado, por supuesto, los estudiantes incorporan una comprensión más sofisticada y la implementación de estos fundamentos.

\footnotetext{
7 Para más información, véase: El patrimonio cultural intangible de China: M eihuaquan (http:// www.meihuaquan.net/mhq/index.asp; en chino), y Yan Zijie (1998). Training M ethods of China Meihuazhuang Weapons (en chino).

8 Un documental en chino centrado en este hecho puede encontrarse en "Asombroso M eihuaquan" http://bugu.cntv.cn/life/humanities/zoubianzhongguo/classpage/video/20091217/100223. shtml (en chino).
}

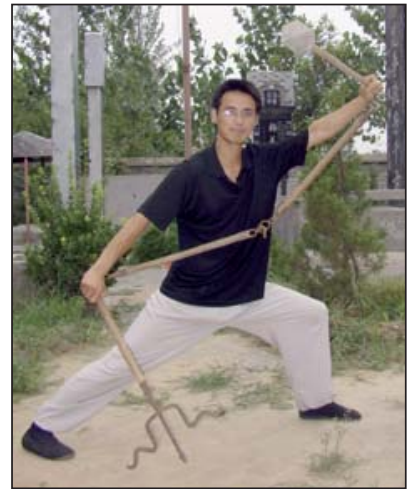

SIIIETANG (HORCA DE CUATRO SECCIONES).

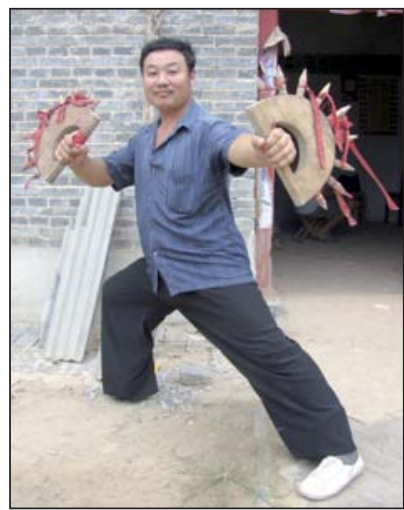

FENGHUOLUN (RUEDAS DE FUEGO).

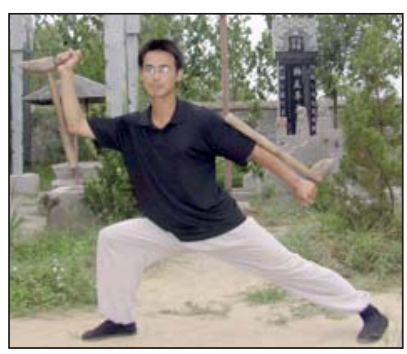

ShuAnggual (BAstones DOBLES DE CUERNO DE BUEY). 


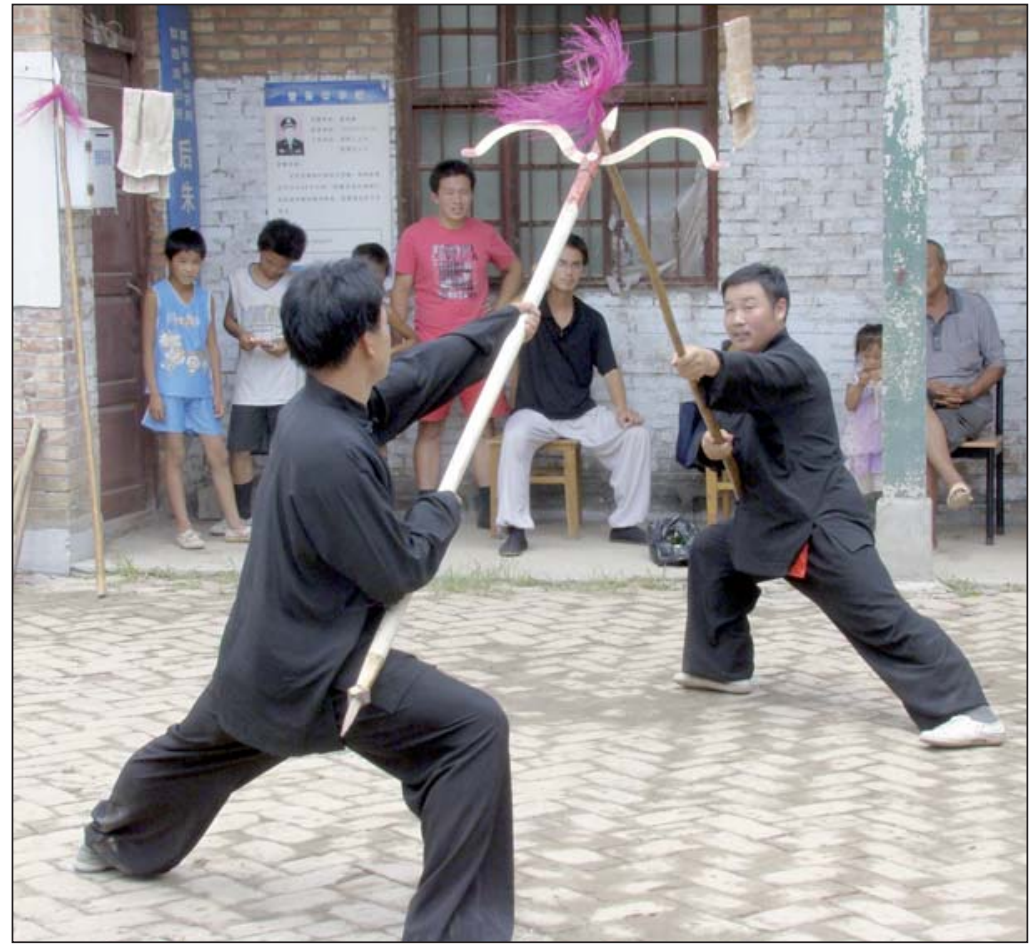

Combate libre CON LOS

RIVALES UTILIZANDO LA HORCA Y LA LANZA.

\section{Conclusión}

El s. XX ha sido testigo de la extinción de muchas artes vernáculas, particularmente artes marciales. La comparación de los relativos niveles de actividad que constatamos en grupos de boxeo rurales, suburbanos y urbanos, y que hemos presentado en la introducción, demuestra que el boxeo mei aún mantiene su vitalidad y un alto grado de elementos tradicionales en el entorno rural a diferencia de los contextos urbanos. Las perspectivas de supervivencia del meihuaquan fueron particularmente malas en el s. XX cuando se vio amenazado por la desaprobación estatal y por el atractivo que suponían los deportes globalizados, tales como el fútbol o el baloncesto, para los jóvenes. ¿Por qué, entonces, un arte marcial que se fundamenta en armas arcaicas (aunque únicas) y en el combate a mano desnuda sobrevive en el S. XXI?

El boxeo de la flor del ciruelo va más allá de la simple defensa personal, es en cambio un fenómeno cultural complejo que se integra en la vida diaria de los practicantes. Los comentarios precedentes demuestran que, a nivel individual, el boxeo de la flor del ciruelo fomenta la habilidad física, proporciona entretenimiento, contacto con lo sobrenatural, y que incrementa el capital social mediante el establecimiento de una red de seguridad a través de los lazos de amistad con la propia familia de boxeo. A nivel grupal, sirve para perpetuar una identidad local y cultural basada en un modelo cultural tradicional frente a la modernización y la amenaza de la descomposición de las lealtades de los pueblos a medida que cada vez más personas se ven obligadas a buscar empleo fuera de su localidad de nacimiento.

En el futuro, existen perspectivas de documentar las tradiciones del boxeo mei de acuerdo a los principios historiográficos más que a través las historias tradicionales de boxeadores mei que han llegado a ser académicos. Estos esfuerzos son estimulados por un Estado que ha llegado a ver el valor de sus artes tradicionales y ahora trata de darles sustento. Globalmente, profesores como el ya citado Yan Zijie han exportado el arte.

Incluso más alentador es el hecho de que los eventos de liangquan ahora se realizan en el condado, en la provincia e incluso nivel nacional. En el 2008, y de nuevo en el 2010, se celebró el Meihuaquan Liangquan Nacional en Liangshan (provincia de Shandong), el hogar legendario de los 108 héroes. Los aprendices llegaron desde lugares tan lejanos como Taiwán, Francia, Italia y Argentina. Claramente en el presente, el liangquan, y presumiblemente el boxeo mei, no solo atrae a los lugareños que hasta la fecha han sido sus seguidores tradicionales, sino que 
también está generando un interés nacional e incluso global (Zhang Guodong, 2010). Sin embargo, estos eventos modernos no profetizan la extinción del meihuaquan tradicional; más bien es probable que dos flujos paralelos, el vernáculo y el "más amplio que lo local" (Shuman 1993), continúen fluyendo uno al lado del otro.

\section{AGRADECIMIENTOS}

Los autores agradecen a Li Yun la lectura de los sucesivos borradores de este trabajo así como sus valiosos consejos.

\section{REFEREN CIAS}

Cohen, P.A. (1997). History in Three Keys: The Boxers as Event, Experience, and Myth. N ew York: Columbia University Press.

Dong, X. \& Arkush, R. D. (1995). The Folk Culture of N orth China. Shijiazhuang: Hebei Education Publishing House.

Esherick, J. W. (1987). The Origins of the Boxer Uprising. Berkeley y Los Angeles: University of California Press.

Fei, X. (2009). Chinese Gentry. Traducido por Zhao Xu-dong \& Qin Zhi-jie. Beijing: Joint Publishing.

Hosbaw m, E. (1969). Bandits. New York: Dell.

Hsu, C. (2006a). The Characteristics of Ancient Chinese Culture. Beijing: Xinxing Publishing House.

Hsu, C. (2006b). Eternal Rivers: The Turning Point and Unfolding of Chinese History and Culture. Shanghai: Literature and Art Publishing House.

Lu, Y. \& Yan, Z. (1990). Exploring the Origin of the Boxer M ovement. Jinan: Shandong University Press.

Meihuazhuang. Disponible en http://www.meihuazhuang.ca [Acceso 10/02/2010].

Peers, C.J. (2006). Soldiers of the Dragon: Chinese Armies 1500 BC-AD 1840. Oxford: Osprey Publishing.

Shi, J. \& Hou, S. (1992). Structure of Feudal Society in China. Kunming: Yunnan University Publishing House.

Shuman, A. (1993). Dismantling local culture. Western Folklore, 52: 345-364.

Sima Qian (109-91 a.C.). Shiji. (Inglés, Records of the Grand Historian). Chinese Text Project. Disponible en: http://ctext.org/shiji [Acceso 10/28/2010].

Zhang, G. \& Li, Y. (2010). Mei boxing as a case: The field investigation and reflection on the intergenerational transmission of folk martial arts. Proceedings of the 21 $1^{\text {st }}$ Pan-A sian Congress of Sports and Physical Education. (Nanchang, China). 


\section{GLOSARIO}

Aizhuang 艾庄

Ao shi 拗势

Badeng Nima 巴登尼玛

Bagua 八卦

Bai shi 败势

Cai Guangrui 蔡光瑞

Caijicun 蔡吉村

Cao Guangchao 曹广超

Caozhou 曹州

Chaodikou 昆堤口

Chenquan 成拳

Zhenwu 真武

Da shi 大势

De 德

Dongmagai 东马垓

Fenghuolun 风火轮

Gaotun 高屯

Gao Yuting (Bitang) 高玉亭（璧堂）

Gengzhuang 耿庄

Han Q ichang 韩其昌

Henan 河南

Heze 菏泽

Houzhuzhai 后朱寨

Hushenpi 护身披

Huo 火

Jiazi 架子

Jiang Jieshi 蒋介石

jin 金

Jiuchengjie 旧城街
Jiugong 九宫

Juancheng 鄄城

Liangchangzi 亮场子

Liangquan 亮拳

Liangshan 梁山

Li Futian 李福田

Li Jinde 李进德

Luwan 辘湾

Ma Chaoshuan 马朝栓

Ma Liang 马良

Meihuaquan 梅花拳

Meihuazhuang 梅花桩

Mu木

Mudanqu 牡丹区

Muli 穆李

Nanguan 南关

Niujiaoguai 牛角拐

Puyang 誉阳

Qi气

Renhuai 任怀

Sang Quanxi 桑全喜

Shandong 山东

Shuangheji 双河集

Shui 水

Shuihuzhuan 水汻传

Shun shi 顺势

Sijietang 四节镗

Sun Bin 孙膑
$\mathrm{Tu}$ 土

W angfang 王坊

W ang Pilian(Jieting) 王丕廉（介挺）

Wang Xianzhi 王仙之

Wang Zhongyun 王中运

W ang Ziping 王子平

Wu Baihua 吴柏华

W uhuben 五虎锱

W u Tipan 吴体胖

Wuzhai 吴寨

Xiao shi 小势

Xiguan 西关

Xing 形

Xiwangtang 西王堂

Xu Jinde 徐进德

Yanchitang 雁翅镗

Yan Zijie 燕子杰

Yangjiaoguai 羊角拐

Yang Shiwen 杨士文

Yang Yuanzhi 杨元芝

Yi 意

Yibensanqiang 一锛三枪

Yihetuan 义和团

Yuguai 鱼拐

Yuncheng 军城

Zhang Congfu 张从富

Zheng Yude 郑玉德

Zou Hongyi 邹宏义 